\title{
Nanocatalysis II: In Situ Surface Probes of Nano-Catalysts and Correlative Structure-Reactivity Studies
}

\author{
Selim Alayoglu • Gabor A. Somorjai
}

Received: 3 October 2014/ Accepted: 6 October 2014/Published online: 18 November 2014

(C) Springer Science+Business Media New York 2014

\begin{abstract}
Model nano-catalysts with monodisperse particle sizes and architectures are essential for a fundamental understanding of surface property dynamics during catalytic reactions. Surface tools and techniques, when conducted under catalytically relevant temperature and pressure conditions, render possible measurements of dynamic surface properties such as oxidation state, composition, coordination, and bonding. Near edge X-ray absorption fine structure (NEXAFS) spectroscopy with purposely built in situ reaction cells and ambient pressure X-ray photoelectron spectroscopy (APXPS) provide (near) surface sensitive and chemical specific information on the oxidation states of metal and oxide (co-)catalysts as well as adsorbent functional elements such $\mathrm{C}, \mathrm{O}$ and $\mathrm{N}$ under reactive gas atmospheres and even liquid environments. Likewise, sum frequency generation (SFG) vibrational spectroscopy with in situ reaction cells helps uncover the bonding geometry and configuration of the topmost surface again under conditions pertinent to catalysis. Furthermore, the local dynamics in the nanoscale and on the single particle level are revealed by environmental transmission electron microscopy (ETEM) and the spectro-microscopy techniques equipped within. A correlative approach, where an array of these in situ tools and techniques were conducted in parallel with catalytic measurements, was employed to gain molecular insight into some of the modern scientific challenges in heterogeneous catalysis.
\end{abstract}

\section{S. Alayoglu · G. A. Somorjai $(\bowtie)$}

Chemical Sciences Division, Lawrence Berkeley National

Laboratory and Department of Chemistry, University of

California, Berkeley, CA, USA

e-mail: somorjai@berkeley.edu

S. Alayoglu

e-mail: salayoglu@lbl.gov
Several case examples of this correlative approach are presented here. The $\mathrm{CO}$ oxidation reaction over hybrid nano-catalysts of $\mathrm{Pt}$ nanoparticles (NPs) with various mesoporous metal oxides such as $\mathrm{Co}_{3} \mathrm{O}_{4}, \mathrm{MnO}_{2}$ and $\mathrm{CeO}_{2}$ was explored in relation to bifunctional catalysis and interfacial charge transfer chemistry by using in situ NEXAFS spectroscopy. Likewise, bimetallic CoPt and PtSn nanoparticle catalysts supported on silica were investigated by using a combination of in situ NEXAFS spectroscopy and APXPS. Next, $\mathrm{CO}_{2}$ hydrogenation was carried out over bimetallic $\mathrm{CoPt} / \mathrm{SiO}_{2}$ and $\mathrm{Co} / \mathrm{TiO}_{2}$ hybrid nano-catalysts. In this case, in situ NEXAFS spectroscopy, APXPS, and ETEM indicated severe, yet reversible, surface restructuring that involved hydrogen atom spillover. Finally, $\sim 2 \mathrm{~nm}$ Pt NPs were investigated using in situ SFG to study hydrogenation and hydrogenative isomerization reactions. Specifically, SFG indicated that the hydrogenation of furfural and crotonaldehyde proceed by interfacial hydrogen atom spillover from $\mathrm{TiO}_{2}$, while the hydrogenative isomerization of methylcyclopentane (MCP) proceeds by spillover and surface diffusion of cyclohexene over mesoporous zeolites. These studies unequivocally indicated the presence of a particular reaction channel that involved one way flow of charged (i.e. electrons or protons) or neutral species (i.e. reactants) at a broadly defined interface between metals and oxides. In addition to these case studies, experimental approaches employing capillary flow micro-reactors are discussed in relation toward the goal of short time resolutions that could help isolate such charged or neutral intermediates in the future.

Keywords In situ NEXAFS - APXPS - In situ SFG · Environmental transmission electron microscopy . Metal-support interaction · Spillover 


\section{Introduction}

Catalysts are often composed of metal and oxide components in the nano-size regimes. Design and fabrication of catalysts has always been the focus of the catalysis field. Less attention has been given to the dynamics that catalysts undergo while in catalytic reaction conditions. Temperature along with the corrosive and reactive gas pressures (and liquid environments) usually tend to alter catalysts. Morphology, redox states, and composition are all fluidic. Although catalysts are purposely tuned and created for specific reactions, in some sense, they will evolve to states that are often different from those of the original catalyst as the reaction progresses. Even though catalyst, by definition, refers to a structurally and chemically unchanged unit, catalytic processes change catalysts. Even the slightest modifications to the original structure and chemistry can alter a catalyst, varying its activity and selectivity away from the type and specifics of the reaction that it was built for.

This should not be a surprise given the strong dependence of the catalytic behavior on the electronic, chemical, and crystallographic states of the metal and/or oxide catalyst materials. The electronic, chemical, and crystallographic structures are closely related and show deviations from expected solid behavior in the nano-size regime [13]. In this regime, size dependence on catalytic activity and selectivity should be expected within a critical range between molecular and bulk limits. Size determines the electronic density of states by altering the band structure of the solid and the crystallographic shape of the catalytic surface by delimiting the outer boundaries of the catalyst material (Fig. 1a). It should also be noted that electronic and crystallographic structures can be tuned independently of size. For example, adsorbate molecules, such as reactants, intermediates or products, can alter both surface electronic states by charge transfer or crystallographic orientation and coordination upon binding. Furthermore, size indirectly establishes the kinetically most stable oxidation state of catalyst. Under net oxidizing and reducing gas atmospheres (or liquid environments) as most, if not all, catalytic reactions have, metals will be oxidized at least on the surface, or equally, metal oxides will be reduced to kinetically meta-stable phases. Particulate or grain size of the catalyst material is one of the sole factors that govern such redox processes.

Catalyst architecture as it applies to bi-functional or charge transfer catalysis is another factor that determines reactivity and reaction kinetics. Metal oxides often function as supports for metal catalysts or act as a co-catalyst along with the metal for the reaction. Metal oxides employed in catalytic transformations vary from inert supports like mesoporous silica (e.g. SBA-15 and MCF-17) to acidic zeolites and basic oxides of 3d-transition metals (e.g. $\mathrm{MnO}_{2}, \mathrm{Fe}_{2} \mathrm{O}_{3}$ and $\mathrm{Co}_{3} \mathrm{O}_{4}$ ), alkali metals $(\mathrm{MgO})$ or lanthanides $\left(\mathrm{CeO}_{2}\right)$. Then, the choice of oxide is to facilitate the direction of charge transfer and/or to introduce additional reaction sites such as to promote the bi-functional character of any particular reaction.

Likewise, the introduction of a second (or even a third) metal either alloyed with the primary metal or as separate reaction centers invoke charge transfer chemistry and bi-
Fig. 1 a Coordination numbers given for 13 -atom and 55 -atom clusters close-packed with facecenter-cubic (FCC) symmetry; and $\mathbf{b}$ distribution of various coordination sites and total coordination numbers as a function of particle size in the $1.5-15 \mathrm{~nm}$ range. Fraction of coordination sites were calculated by using the algorithms reported by van Hardeveld and Hartog [1]

\section{Particle Size vs. Coordination}

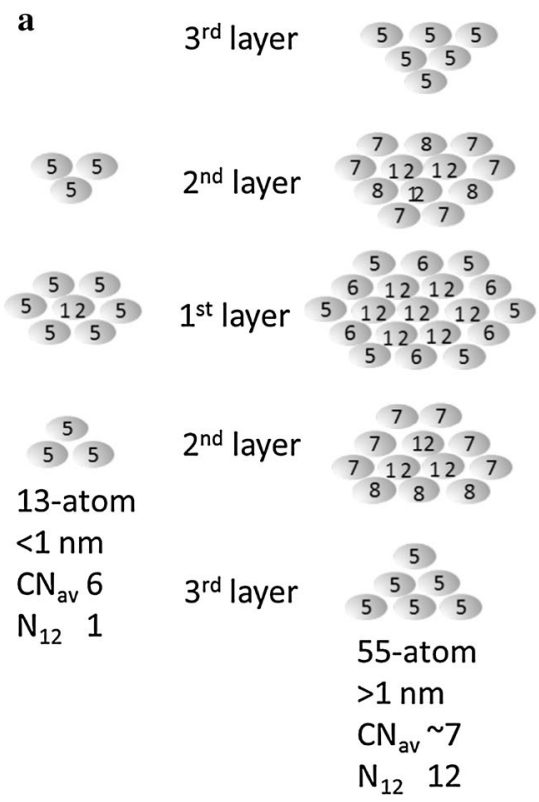

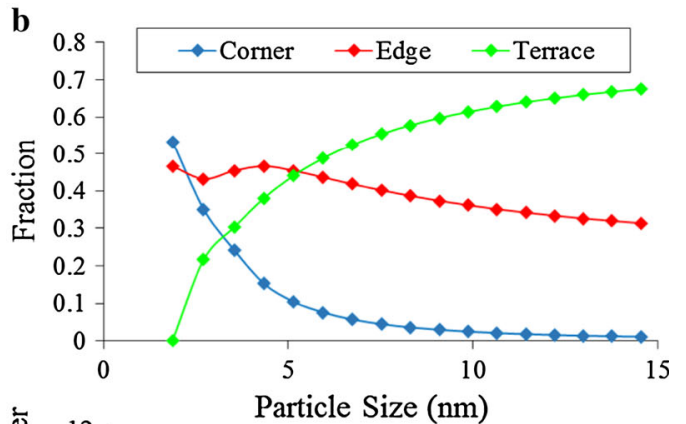

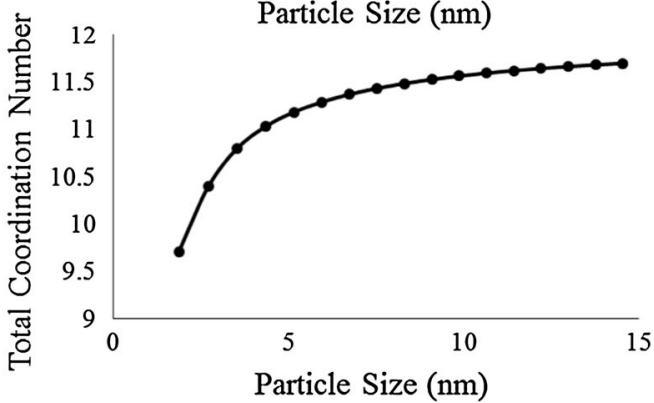


Fig. 2 Representative nanocatalyst architectures, composed of more than one component, discussed in this study: metal/ oxide hybrid composites and bimetallic particles. Some alloy surface ensembles are also depicted in relation to the bimetallic architectures
Particle Architecture

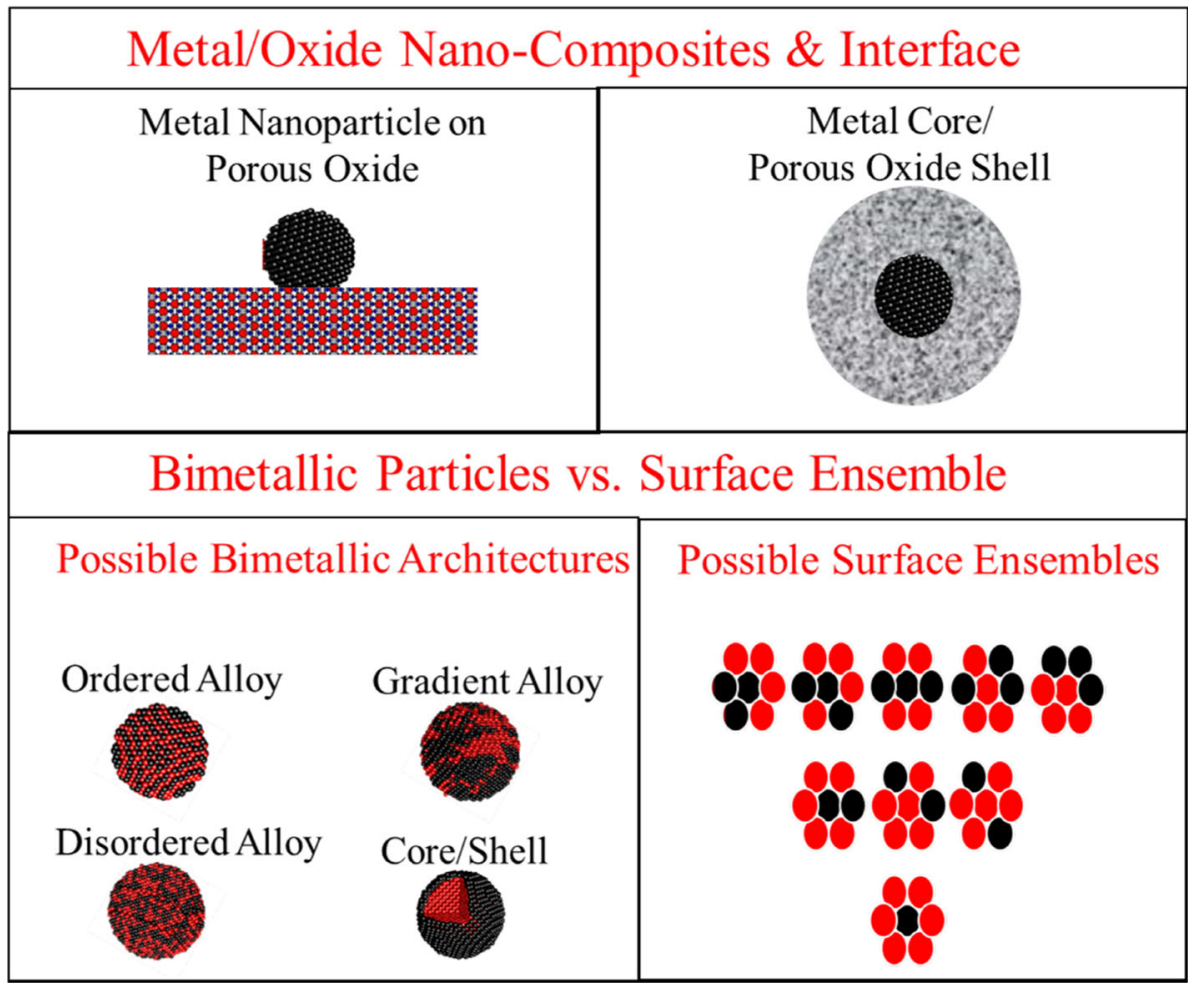

functional catalysis. Possible architectures for systems with more than one metal are, in the order of decreasing short range order between the components, intermetallic (i.e. ordered alloy), homogeneous random alloy, gradient alloy, core/shell and dimer hetero-aggregates (Fig. 2). The complexity exponentially increases with the number of metals and relative elemental ratios. In principle, there is an infinite number of particle architectures in compositional space which are governed by the microscopic arrangement of different metal atoms in the bulk and on the surface (as an example, see Fig. 2). As a result of such a large microstructural space, bulk coordination and surface ensembles vary dramatically with particle architecture, as does the catalytic behavior. In general, charge transfer effects, driven by a net electronegativity difference between the metal components as predicted by Norskov's 'surface reactivity theory' $[4,5]$, and surface ensemble effects, based upon the short-range order, are more pronounced for intermetallic catalysts. Electronic and geometric effects, induced by strain and orbital overlap as predicted by 'near surface alloy theory' [6, 7], are put forward fundamentally for core/ shell catalysts.

Given this complex network of structure-size (or architecture) relations, it should be noted that precise and accurate knowledge of the initial states of a catalyst is necessary to develop any chemical insight into catalysts' function during catalytic reactions in general. After all, metal and oxide nanoparticles are prepared under synthetic conditions that are different from the reaction conditions, and are kinetically trapped in the pre-catalysis forms. However, the dual effect of time and temperature acts to transform working catalysts into forms that are more stable under reactive/corrosive gas atmospheres (or liquid environments). Particle sintering and crystal phase transformations are typical results of prolonged time-on-stream operations of catalyst materials which present further complications in drawing any unambiguous conclusions concerning how catalyst materials function.

From a catalysis point of view, the control of size and phase presents an intriguing and rewarding way of tuning the desired activity and selectivity expected of any particular catalyst. Furthermore, nano-catalysts with welldefined electronic, chemical and crystallographic properties are essential to multi-path and multi-product catalytic reactions, where high activity and $100 \%$ selectivity are targeted for particular end-products. The design and synthesis of such model catalysts, for which particle size and catalyst architecture can be fine-tuned, are essential for developing a unique understanding of active states and fundamental reaction pathways of catalytic processes that could lead to a better understanding of catalysis in general. In this respect, colloidal chemistry and other bottom-up 
techniques (e.g. sol-gel and solvo-thermal synthesis; e-beam and thermal evaporation; vapor deposition) offer synthetic tools and strategies to achieve the fabrication of size- and architecture-controlled nano-catalysts.

It should be noted that capping ligands are employed in colloidal synthesis to stabilize NP size and/or morphology, and they may have impact on catalyst properties, namely catalytic activity and selectivity. The documented behaviors vary from inhibitory effects, such as a surface poisoning observed for size-controlled Co NPs co-stabilized with phosphine oxide ligands during $\mathrm{CO}_{2} / \mathrm{H}_{2}$ reaction; [8] and promotional effects, such as a ligand-induced creation of active surface ensembles in the case of thiol-stabilized monometallic Pt and bimetallic Au-Pt NPs for hydrodesulfurization reactions [9]. Partial activity losses were also reported for Suzuki coupling [10], ethylene hydrogenation [11-13], and the hydrogenative isomerization of methylcyclopentane [14] when using polymer (e.g. PVP) caps, and $\mathrm{CO}$ oxidation when using amine functional ligands, which were attributed to partial surface blocking effects. However, no electronic or geometric effect of surface ligands on nano-catalysts has been reported to date.

The importance of utilizing nanoparticles with monodisperse particle sizes and architectures and oxide supports/ co-catalysts with controlled pore structures, surface areas, and surface functionalities as model catalysts has been discussed in the first part of this review. The subsequent sections, however, are focused on the material dynamics of such well-behaved nano-catalysts through the use of in situ tools and techniques.

The dynamic aspect of catalysis underlies the importance and necessity of in situ and in operando studies. It should be noted that the term in situ is used whenever the probe technique is employed under the reaction conditions without in-line catalytic measurements; in operando refers to simultaneous measurements of catalytic and materials properties. For in situ studies, the catalytic information comes from catalyst testing which is usually conducted in parallel scaled-up reactors under similar temperature and pressure conditions as the probe experiment. The objective of this review is to give accounts of in situ (and some in operando) experiments on model nano-catalyst systems that led to a better understanding of catalytic behaviors and trends in particular reaction processes.

This paper is organized in two sections. In the first section, in situ surface tools will be reviewed. They are classified in three categories: electronic spectroscopy, vibrational spectroscopy and electron microscopy. In the electronic spectroscopy category, X-ray absorption and photoelectron spectroscopies will be introduced as chemically sensitive surface probes. Then, sum frequency generation (SFG) vibrational spectroscopy and surface enhanced Raman techniques will be discussed in the vibrational spectroscopy category as tools that have submonolayer sensitivity towards immediate catalyst surfaces. Finally, transmission electron microscopy (TEM) techniques such as bright field and dark field imaging and electron diffraction will be described in relation to studies in catalysis. Along these lines, scanning transmission electron microscopy (STEM) and spectroscopic tools that use the scanning electron beam as a local probe will also be discussed. In general, the technical definitions of each tool will be given, followed by the basic components and key elements of in situ setups. Most of these tools are employed in the Somorjai group routinely to investigate the surface reactivity of model heterogeneous catalysts with bimetallic nanoparticle and metal/oxide nano-composite architectures.

In the second section of this paper, some case examples will be discussed in which the described in situ surface tools, individually or in combination, have been employed in conjunction with catalytic measurements to address structure-reactivity correlations. These case examples are grouped under four catalytic reaction categories: $\mathrm{CO}$ oxidation, $\mathrm{CO}_{2}$ hydrogenation, hydrogenative reforming of hydrocarbons, and heterogenized homogeneous transformations in organic liquids.

\section{Probing Tools of Catalysis}

Because catalysis is a surface phenomenon, the probing tools and techniques that are employed to provide structural information should exhibit a certain level of sensitivity towards surfaces or near surface regions. Furthermore, chemical sensitivity towards high-Z elements constituting catalyst and surface-adsorbed molecules should be achieved. Orientations and binding configurations of adsorbate molecules should also be addressed in order to obtain a full molecular picture of the catalyst. Additionally, structure-reactivity correlations are based on the assumption that catalysts are uniformly behaved within the probe size when bulk ensemble averages of the catalytic system are monitored; it is a matter of the spatial resolution or the probe size which will lead to identical information at the microscopic level. Hence, spectromicroscopy has a special place in our efforts to reconcile structure and catalytic behaviors with trends, and correlative spectroscopy and microscopy studies should be included within this framework. Finally, probe-matter interactions should be accounted for and ruled out properly. The probe is often a collimated light (i.e. synchrotron $\mathrm{X}$-rays, lasers in IR/Vis/UV wavelengths) or electron source; or a molecule, which exhibits a unique spectral (i.e. vibrational) signature upon adsorption. Thus, the probe can, in principle, perturb catalyst surfaces in such a way as 


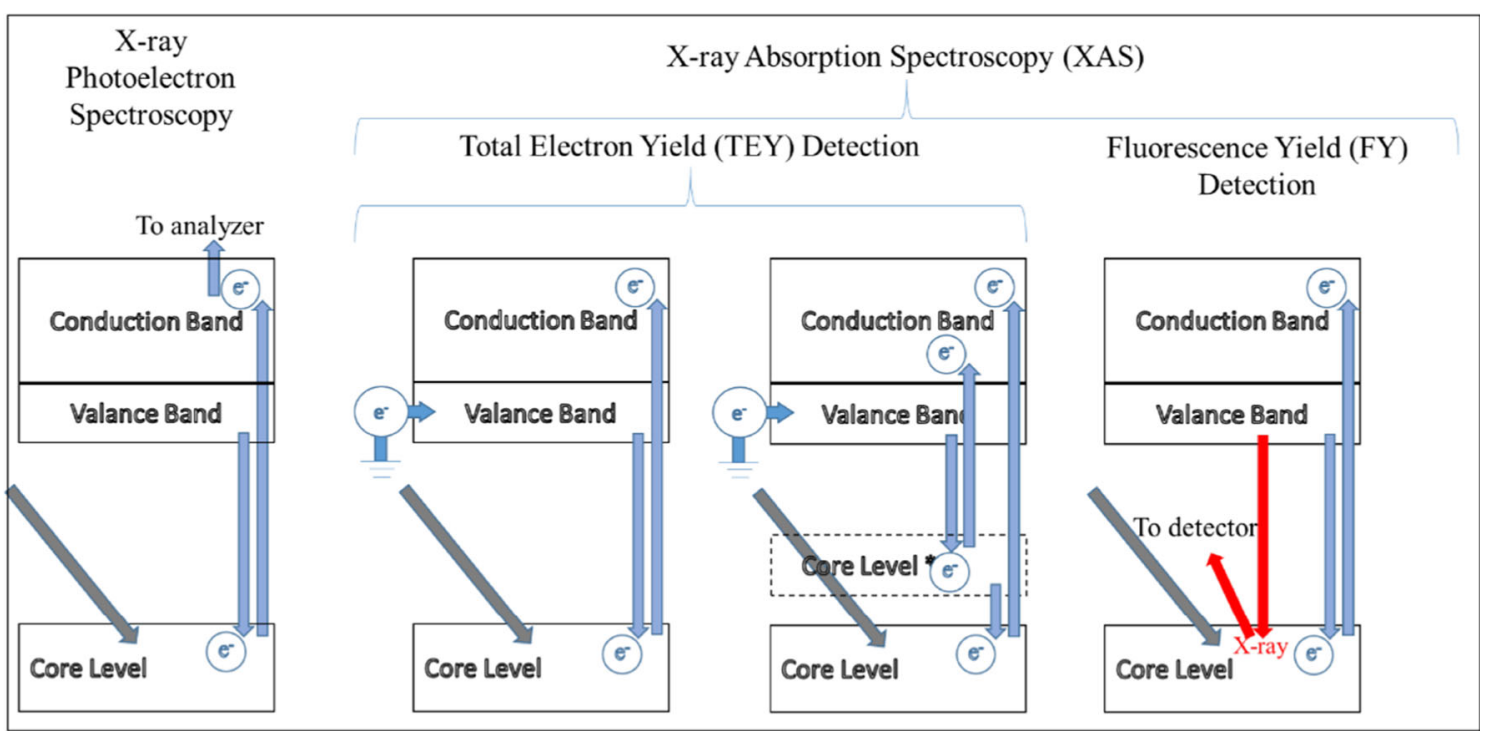

Fig. 3 Schematics showing the electronic principles of X-ray photoelectron spectroscopy (XPS) and X-ray absorption spectroscopy (XAS). Two modes of detection for XAS are also depicted

to alter the kinetics and steady-state behaviors of ongoing catalytic reactions.

\subsection{Electronic, Chemical and Crystallographic Structures of Catalyst Materials via X-ray Spectroscopic Techniques}

Synchrotron X-rays serve as excellent probes of electronic structure and coordination on the surface and in the near surface regions. Specifically, core level excitations from impinging soft $\mathrm{X}$-rays, in the energy range of $100-1,100 \mathrm{eV}$, give rise to dipole-induced transitions at the ionization threshold which generate photoelectrons, secondary (Auger) electrons and inelastically-scattered photons (Fig. 3). Photoelectrons and Auger electrons are element specific and detection of these electrons is very surface sensitive owing to their short mean free paths in solids. Although typical penetration depths of soft X-rays at the shallow absorption edges of the elements are several hundreds of nanometers, electrons from only the top few nanometers of the surface can escape any solid. This is usually the case for L-edge absorption of 1st row (3d) transition metals such as $\mathrm{Mn}, \mathrm{Fe}$ and $\mathrm{Co}$; M-edge absorption of 2nd row (4d) transition metals; and N-edge absorption of 3rd row (5d) transition metals. For instance, X-rays with photon energies of the $\mathrm{Co}_{3}$ step edge have attenuation lengths of $800 \mathrm{~nm}$, defined as the length for a drop of intensity by $1 / \mathrm{e}$, while electron yields are entirely registered from the topmost $2.5 \mathrm{~nm}$ of surfaces [15]. Furthermore, simultaneous measurement of $\mathrm{X}$-ray emission provides the complimentary bulk detection.
In addition to surface detection, the X-ray absorption process is dipole induced, so that surface selection rules apply to the transitions. As a result, the orientation and binding configurations of surface adsorbed molecules can be obtained for single crystal surfaces, and in principle preferentially oriented nano-crystalline catalysts, by tilting the sample with respect to the incoming X-ray beam. Tilt series of X-ray absorption spectra obtained in this way can reveal the relative strength of various orbital transitions with respect to the surface dipole; molecular orientation can then be deduced from this angular variation in absorption intensities. The tilt studies can be achieved using soft $\mathrm{X}$-rays to measure the $\mathrm{K}$ edge absorption of low$\mathrm{Z}$ elements such as $\mathrm{C}, \mathrm{N}$ and $\mathrm{O}$ [16-18]. Furthermore, electron yield can be detected in gas atmospheres or condensed phases (as opposed to X-ray photoelectron spectroscopy) by simply measuring the amplified compensating electron flow from earth to sample.

\subsubsection{X-ray Absorption Spectroscopy}

$\mathrm{X}$-ray absorption gives rise to two complementary processes, which are identified as near edge X-ray absorption fine structure (NEXAFS) and extended edge X-ray absorption fine structure (EXAFS). The former technique, as the name implies, refers to the dipole-induced electronic transitions near absorption edges, which is usually $5-50 \mathrm{eV}$ above the core level being excited. It is also known as $\mathrm{X}$-ray absorption near edge structure (XANES), which is synonymous with NEXAFS. Generally, the shallower the core level being excited, the higher the energy resolution is because of longer core-hole lifetimes (i.e. Heisenberg 
uncertainty principle). Furthermore, upon X-ray absorption shallow core levels emit electrons that are highly surface sensitive. Hence, soft X-ray absorption spectroscopy is usually the preferred mode of application in catalysis for this technique. Two-dimensional nanoparticle films and adsorbate molecules at sub-monolayer coverages can be detected by using soft NEXAFS spectroscopy.

EXAFS concerns the extended energy range beyond what is defined for the near edge region. It is discerned by oscillations in the extended spectrum that arise from near neighbor interactions $\mathrm{X}$-rays incident on absorber atoms give rise to wave fronts that are scattered from neighboring atoms which, in turn, give rise to interference patterns which modulate the absorption. Amplitude (in real space) and phase (in reciprocal space) of such oscillations of the absorption can be analyzed by using physically welldefined structural models to obtain the involved crystallographic variables such as coordination number, atomic distances, and thermal displacements. Because Fourier transformation, which is mathematically applied to EXAFS data to obtain the phase and amplitude, requires a summation over a large set of k-points, the EXAFS technique can only be used for X-ray absorption studies involving deeper core levels: K edge absorption for 1st and 2nd group transition metals and $\mathrm{L}_{3}$ edge absorption of 3rd group transition metals. This restricts the use of the EXAFS technique to bulk phenomena regardless of the detection mode used. Photoelectrons from shallow core levels possess high kinetic energies sufficient to travel from much deeper than near surface regions, and contribute to the background on one hand. Auger electron emission from deep core levels, on the other hand, contribute selectively to the near edge region pass the edge jump. Although the probability of Auger transitions involving shallow core levels is relatively high, more energetic secondary electrons from deeper core levels have larger escape depths rendering their contribution to the total electron yield significant. Therefore, total electron yield is not strictly confined to the near surface regions, but carries information from the bulk as well.

Nonetheless, for clusters and small nanoparticles, where bulk practically becomes surface (i.e. large surface-tovolume ratios), the EXAFS technique can be recognized as surface sensitive and thus is relevant to catalysis studies [19, 20] (see Fig. 1b). It should be noted that coordination number for close-packed metals varies steeply with particle size in the size range of interest for catalysis. For instance, coordination number jumps from an average of 7 for a $1 \mathrm{~nm}$ cluster, composed of 50 atoms about $80 \%$ of which are on the surface, to an average of 11 for a $3 \mathrm{~nm}$ nanoparticle, where about 250 out of 800 atoms are registered on the surface, as illustrated in Fig. 1. The picture gets even more complex when more than one atom type is involved, given the large permutational space (see Fig. 2). Then, structural models can only be employed for model nano-catalysts with monodisperse particle size and architecture distributions.

All these aspects make soft X-ray absorption spectroscopy (XAS) a unique technique to study catalyst surfaces. In order to obtain an X-ray absorption spectrum, relative absorption intensities across the absorption edge of elements should be recorded. This is only possible when monochromated X-rays with tunable energies are employed; and thus, in practice, requires synchrotron radiation facilities. Soft XAS is an ultra-high vacuum (UHV) technique because of the strong interaction of $\mathrm{X}$-rays with matter. The attenuation lengths of $\mathrm{X}$-rays in gas atmospheres are on the order of several millimeters and much shorter in condensed matter. To prevent large signal drops while maintaining ambient gas pressures above the sample, a common strategy is to separate reaction environment from the upstream synchrotron by using windows transparent to X-rays above $100 \mathrm{eV}$. Aluminum and silicon nitride membranes are typically employed as soft X-ray windows; $100 \mathrm{~nm}$ thick membranes are usually mechanically strong enough to hold differential pressures while transmitting X-rays in a broad energy range with high \% transmittance. In this context, reaction cells operating in static [21] or flow modes [22-26] for liquids and various reactive gases can be purposely built and utilized in UHV chambers for soft XAS, as shown in Fig. 4.

\subsubsection{X-ray Photoelectron Spectroscopy}

Differently than XAS, XPS can use a constant, monochromated or not, photon source to excite the related core levels. Then, ejected photoelectrons are analyzed to generate photoelectron spectra. This aspect of XPS allows it to be employed as a benchtop laboratory tool. However, synchrotron radiation offers high X-ray fluxes with tunable photon energies. Combined with the fact that inelastic mean free paths of photoelectrons strongly depend on the photon energy, one can vary photon energy to map surface and near surface regions at different depths, a technique known as depth-profiling.

X-ray photoelectron spectroscopy (XPS), like soft XAS, is an UHV technique, because of the short mean free paths of photoelectrons. As opposed to XAS, photoelectrons should travel through UHV to the analyzer where they are sorted out as a function of kinetic energy that they carry. In addition, short mean free paths of photoelectrons in solids, typically ranging from several Angstroms to a few nanometers, also hinder the use of any practical window. One exception to this is the use of single- or multi-layer graphene, which is yet awaiting a successful implementation in XPS measurements. 
Fig. 4 a Schematics illustrating an in situ XAS cell; and $\mathbf{b}$ a purposely-built gas flow cell in use in the Somorjai group and c picture showing the in situ gas flow cell during operation in beamline 8.0.1 at the advance light source

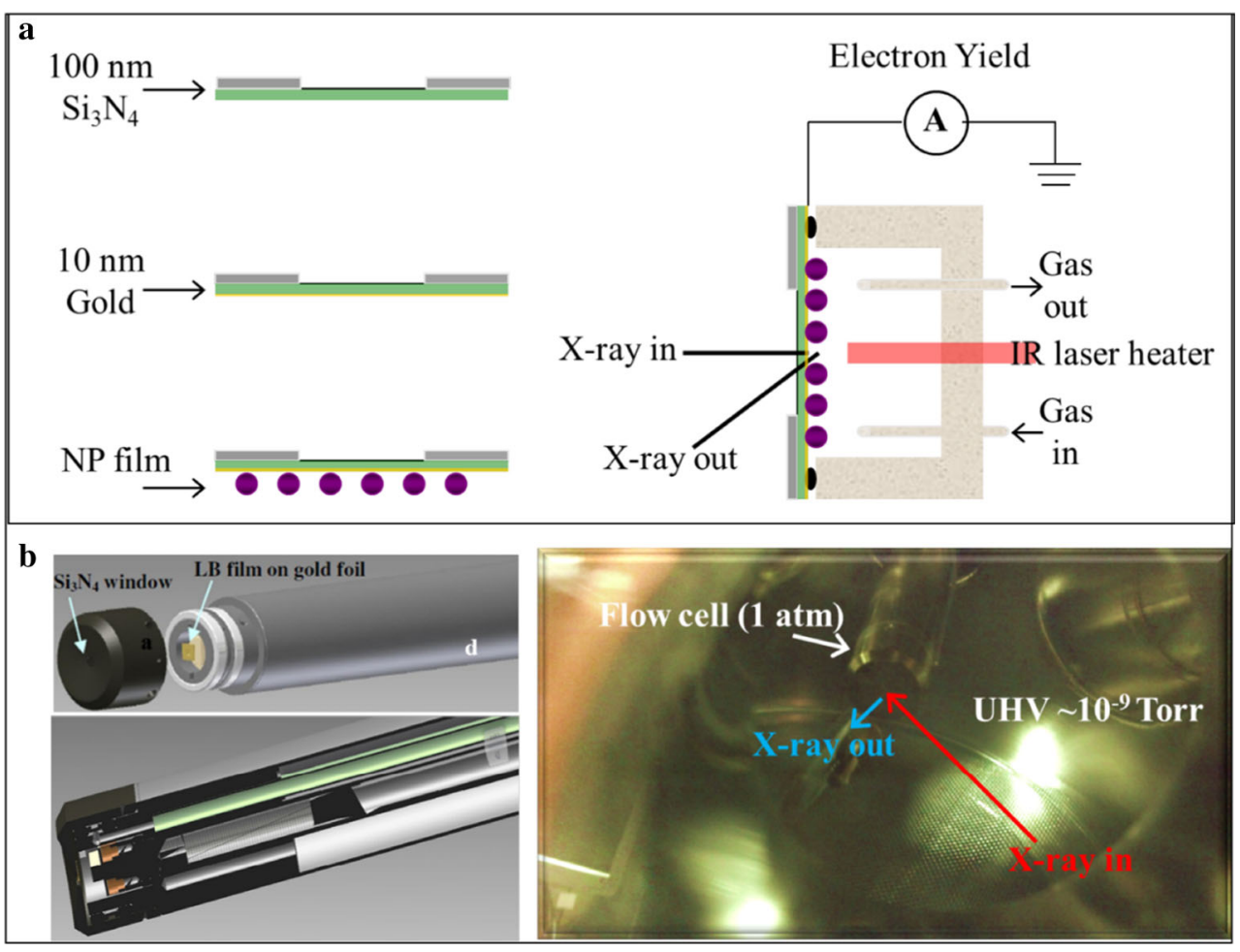

In ambient pressure (AP) XPS, a technique that successfully overcame the inherent restrictions of traditional XPS, photoelectrons are captured before they are lost to collisions with the surrounding ambient medium by using a small aperture cone located in the proximity of the sample [27-29]. Gas molecules are then differentially pumped through the aperture while photoelectrons are focused using electron lenses on to the analyzer, which is eventually pumped down to UHV [27]. By this way, ambient gas pressures in the Torr regimes are made possible in XPS measurements. Recently, another milestone in the technique came when tender X-rays in the $2,000-5,000 \mathrm{eV}$ range were used to create photoelectrons from a thin solid/liquid interface, which opened up roads to unprecedented experiments for in situ and in operando studies [30].

It should also be noted that working gas pressures inside APXPS cells, although in the low Torr ranges, are of relevance to catalysis with measurable turnovers. APXPS with energy tunable synchrotron X-rays renders probing the immediate catalyst surfaces as well as the interfaces between metal and oxide support of model catalysts. Moreover, the chemical foundations in the nanoscale of surface phenomena such as wetting, encapsulation and coverage can be understood by using APXPS; and thus structure-function correlations can be derived for model nano-catalysts with fine chemical details never before observed as the catalytic reaction occurs.

\subsection{Surface Orientation and Molecular Bonding via Vibrational Spectroscopy}

The other extreme of the optical spectrum, specifically the far IR region, is often employed for vibrational and Raman spectroscopy. Although the excitation wavelengths range from mid UV to far IR the spectral region of interest falls in the $100-4,000 \mathrm{~cm}^{-1}$ window, where IR vibrations and Raman scattering occur. The topmost surface where catalytic reaction events take place can be distinguished by adsorbate molecules, bound to metal and/or oxide catalysts, in their activated states. Spectral isolation and identification of such states leads to the understanding of catalytic reaction pathways and even mechanisms when employed in conjunction with catalytic measurements conducted in parallel with spectroscopy. However, surface specific detection is an absolute must, given the relatively short absorption lengths of IR in the gas phase. Therefore, traditional IR and Raman techniques should be treated with caution when employed in catalytic systems. IR techniques like polarization-modulation IR reflection absorption spectroscopy (PM-IRAS) and non-linear optical techniques like SFG can be singled out as surface sensitive vibrational tools [31].

PM-IRAS is based on modulating polarization of IR light at high repetition rates compared to vibrational stretch frequencies, and has been used on model catalyst systems such as thin metal/oxide films, two-dimensional films of 
Fig. 5 a Sum frequency generation process, $\mathbf{b}$ schematic of an in situ SFG reaction cell; and $\mathbf{c}$ picture showing the in situ SFG gas flow cell in use in the Somorjai group
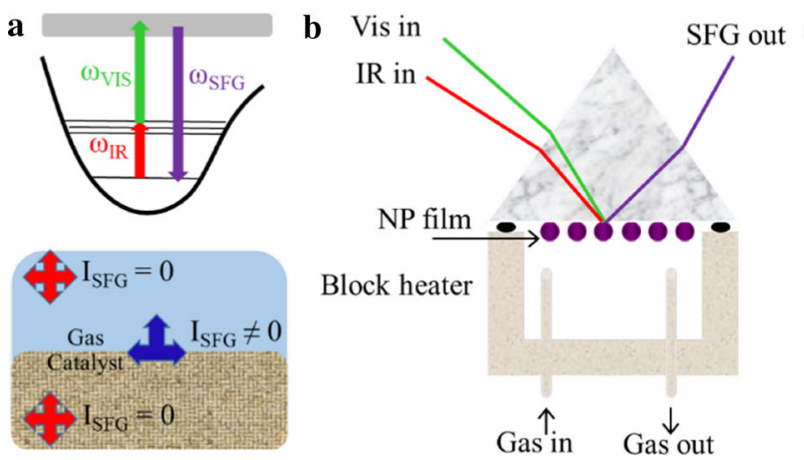

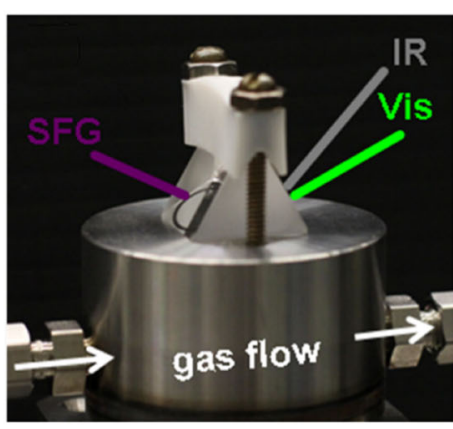

nanoparticles (e.g. thermally evaporated, e-beam deposited, etc.) and their combinations [32, 33]. The coupling of constructively and destructively polarized light with in phase (p-polarized) and out of phase (s-polarized) components of surface adsorbed molecules give rise to an orientation dependence governed by surface selection rules. This is achieved by illuminating the surface at grazing angles, where the intensity of outgoing p-polarized light $\left(l_{p}\right)$ is at a maximum, whereas the intensity of outgoing s-polarized light $\left(1_{\mathrm{s}}\right)$ is not dependent on the incident angle. Hence, a surface enhancement is obtained for species with vibrational components parallel to surface normal when the IR spectrum is recorded as a plot of $\left(l_{p}-l_{s}\right) /$ $\left(1_{\mathrm{s}}+1_{\mathrm{p}}\right)[34]$.

In SFG vibrational spectroscopy, collimated and pulsed light beams (i.e. lasers) at visible and tunable mid IR wavelengths are temporally and spatially overlapped on model nano-catalysts. The light generated at summed frequencies is collected in total internal reflection geometry. The measured SFG signal is given by the electric field strengths of incident electromagnetic waves and the nonlinear susceptibility. The non-linear susceptibility has both a resonant and non-resonant component. The resonant component of the non-linear susceptibility is fundamentally a sum of all bond dipoles, but for centrosymmetric environments, where a time-average of the ensemble of dipoles is in principle zero (as in bulk gas or liquid), the SFG signal cancels out. Therefore, the SFG signal is only non-zero for non-centrosymmetric media such as interfaces and surfaces, where inversion symmetry is broken. The non-resonant component of the non-linear susceptibility is, however, not well modeled, and requires control methodologies in experimentation, especially for SFG studies that involve metals, where non-resonant effects have been found to be significant.

It was found for SFG experiments that a total internal reflection geometry using a prism is best suited for maximum SFG signal output [35]. Towards this goal, entrance angles of laser beams should be carefully aligned using the prism while maintaining the temporal and spatial overlap.
Short attenuation lengths of the evanescent waves, on the order of tens of nanometers, limit the probed area to near surface regions of the sample, either in contact with the prism [36] (Fig. 5) or across an ultrathin layer of aqueous electrolyte [37] that separates the sample and prism. For the reasons described above, the sample volumes employed in SFG studies are usually very small, which renders model systems like metal nanoparticles dispersed over thin films of oxides ideal.

In a typical SFG setup for catalysis studies, a 1,064 nm Nd:YAG laser generating pulses in mJoules and with picosecond bandwidths is used as a seed source to pump frequency-doubled pulses in the visible spectrum $(532 \mathrm{~nm})$ and broadly tunable IR pulses in the $2,500-4,000 \mathrm{~cm}^{-1}$ spectral range. The oscillating visible and tunable IR pulses are synchronized and spatially overlapped at a prism with the nano-catalysts located on it or in its vicinity. A resonant SFG wave is generated wherever and whenever an evanescent wave at a given IR frequency resonates vibrationally with the adsorbate molecules.The SFG spectrum is then obtained by scanning IR frequencies in the desired spectral window. It should be noted that the resonant vibrational modes associated with the SFG signal should have both IR- and Raman-active symmetries.

It is worth mentioning that molecules chemisorbed on metal (or metal oxide) surfaces usually display net nonzero dipole moments and polarizability. This property of heterogeneous systems (i.e. solid-liquid and solid-gas) renders SFG an attractive technique for in situ/in operando studies, as highlighted in a number of studies spanning single crystals $[38,39]$ as well as two dimensional films of nano-catalysts [40-43].

Raman inelastic scattering is a vibrational technique as well as a tool for optical phonon mode and crystal phase determinations. When used in catalysis it provides bonding information for reactant molecules, adsorbed species on catalyst surfaces, and catalysts, in particular metal oxides [44]. In the micro-Raman technique, the sample is excited with a laser source, typically a continuous wave in the visible spectrum, through the objective lens of an optical 
microscope. Inelastically scattered light is then collected by the same objective lens and Raman shifts are measured by using a charged coupled device after filtering out the laser line. By this method, spatial resolutions in the diffraction limit of the light can be achieved as well as high signal intensities. However, the Raman technique, inherent to its optical nature, is not surface specific.

A major breakthrough that enables the application of the Raman technique in heterogeneous catalysis, and surface studies in general, came with the resonant surface enhancement effect for coinage metals such as $\mathrm{Au}$ [45], $\mathrm{Ag}$ [46, 47] and $\mathrm{Cu}$ [48]; and noble metals such as Pd [49] and $\mathrm{Rh}[50,51]$. The coinage metals exhibit surface plasmons, collectively oscillating electrons localized on surfaces, when excited with the visible region of the electromagnetic spectrum. When excited with the visible light, surface plasmons become resonantly oscillating. The so-called 'hot electrons' due to such resonant absorption processes then enhance electromagnetic fields near the surface and decay away from the surface. As a result of this resonance enhancement, at such 'hot spots', the Raman process is amplified orders of magnitude compared to the non-resonant operations [52, 53]. Furthermore, enhancement factors were found to be greater when the metals are in the nanoscale and along sharp edges and corners when metal nanoparticles have unisotropic morphologies [54]. It was also found that thin dielectric coatings around these surface Plasmon resonance (SPR) active metal nanoparticles cause red shifts in the absorption spectrum and thus further facilitate the enhancement effects. This phenomenon presents tremendous opportunities for heterogeneous catalysis because the Raman scattering from the vicinity of SPR-active metals becomes statistically significant. As a result, when the active catalyst surface is located in the atomic proximity of the SPR-active metals the Raman signal can be amplified to a level that renders high sensitivity detection possible. This is the fundamental principle behind tip-enhanced Raman spectroscopy, in which Raman scattering was facilitated by an AFM tip made out of a SPR-active metal. By using the SPR enhancement phenomena, spatial resolutions on the order of tens of nanometers [55, 56] or single (adsorbate) molecule detection was reported as a proof of concept [57].

\subsection{Size, Morphology and Chemical Structure Via Transmission Electron Microscopy Techniques}

Transmission electron microscopy (TEM) is often employed for studying catalysts, specifically pre- and postcatalysis investigations of morphology, crystallography, and chemical states of catalysts [58-63] [38]. In TEM, electrons are transmitted through the solid and produce contrast patterns based on varying degrees of transmittance through an objective lens of the primary beam (bright field imaging) or the diffracted beams (dark field imaging) across the sample. Image patterns are two dimensional projections of solid objects and can reveal morphology, atomic planes, and individual atoms in periodic arrays when the sample plane is oriented relative to the electron beam in such a way that electrons are diffracted at Braggs' angles in the confined q-space of the high energy electron optics. Furthermore, electron diffraction patterns can be collected to obtain periodicity and even crystal phase.

\subsubsection{Scanning Transmission Electron Microscopy}

STEM, a spin-off technique, goes beyond the capabilities of conventional TEM and renders local structure analysis of solids possible. In STEM, the electron beam is focused to a small spot size, typically a nanometer in diameter, and is used as a local probe in the raster mode. Annular dark field (ADF) imaging is one of the techniques that can be employed in the scanning mode. ADF is achieved at short camera lengths, which requires small probe sizes. Because it is classified as a Rutherford type scattering, it is the elemental nuclei that electrons interact with, as opposed to soft electron orbitals in conventional DF imaging [64]. Therefore, ADF imaging is identified with high Z-contrast. Model catalysts are multielement composites and are often composed of a crystalline metal sparsely dispersed on a matrix of porous and thick metal oxide. In conventional TEM, thickness and diffraction contrast contribute to image formation as Z-contrast in conventional DF, complicating analysis. However, ADF in the scanning mode decouples the effects of atomic number, thickness, and diffraction, and provides local Z-enhanced information. In this way, model catalysts can be studied with greater elemental and structural sensitivity.

It is also worth mentioning that after the transmission electron aberration-corrected microscopy (TEAM) project $[65,66]$ was realized, probe-corrected electron microscopes brought cluster-sized nanoparticles and even single metal site coordination complexes into the repertoire of TEM studies [67, 68]. Furthermore, aberration-corrected electron microscopes can operate at low accelerating voltages (i.e. $80 \mathrm{kV}$ ) and low electron dose exposures (i.e. several electrons per square Angstrom); and thus allow imaging that is free of knock-on atom displacements and ionization effects $[69,70]$.

It is also common practice to equip analytical tools such as energy dispersive spectroscopy (EDS) and electron energy loss spectroscopy (EELS) with the TEM operating in the scanning mode. EDS probes elemental composition for almost the entire periodic table with the exception of low $\mathrm{Z}$ elements, while EELS explores chemical fine structure as well as elemental composition for elements with $\mathrm{Z}<30$ [71]. Therefore, both techniques complement 
each other. In some aspects, EELS is reminiscent of NEXAFS, probing the electronic structure of solids such as $\mathrm{Co}, \mathrm{Fe}$ and $\mathrm{Mn}$; while electron energy loss fine structure (EELFS) spectroscopy [72], a technique derived from EELS, replicates the EXAFS model to obtain near neighbor bonding for elements such as $\mathrm{O}, \mathrm{Al}$ and Si [71, 72]. Fundamentally, all the sought after elements of as-synthesized (or spent) catalysts such as size, morphological and geometrical shapes, phase, composition, oxidation state, and bonding can be studied in TEM.

Strong electron-matter interactions limit the TEM technique traditionally to high vacuum conditions. Environmental TEM [73], in which gas atmospheres in the Torr pressures can be dosed into the sample area in a fashion similar to APXPS, can be considered as revolutionary in the catalysis field. Recently, new developments and advances in micro-machining and membrane technologies allowed another breakthrough toward mimicking realistic catalytic environments in the TEM column. By using static and flow gas/liquid cell holders, catalysts can be studied in their working environments, either as individual nanocatalysts or composite catalyst ensembles. Then, a statistical data pool for microscopic catalytic reaction pathways can be identified as compared to the ensemble averaged macroscopic reaction pathway.

\section{Case Examples of In Situ Studies of Model NP Catalysts}

In situ surface techniques along with catalytic measurements play key roles in identifying the structure-reactivity properties as well as deciphering the complex catalytic behaviors and trends. When employed in studying model catalysts, of bimetallic or metal/oxide hybrid natures, in situ tools are the experimentalists' five senses to the chemical and catalytic events as they occur. In this section, some case studies of model nano-catalysts that illustrate a correlative approach of in situ probing and catalytic measurements will be discussed. These case examples are grouped into four categories that are distinguished by the type of catalytic reaction: $\mathrm{CO}$ oxidation, $\mathrm{CO}_{2}$ hydrogenation, hydrogenative reforming of hydrocarbons, and heterogenized homogenous transformations in organic solvents.

\subsection{Catalytic CO Oxidation over Pt/Mesoporous Metal Oxide Nano-Composite Catalysts and Pt-Based Bimetallic Nano-Catalysts}

Catalytic oxidation of $\mathrm{CO}$ is a model reaction to evaluate catalyst activity. Pt is a model metal catalyst and shows a weak dependence of crystal shape or size in the nanoscale on catalytic turnovers to $\mathrm{CO}_{2}$, when used alone [74] or along with inert supports such as $\mathrm{SiO}_{2}[75,76]$ and $\mathrm{Al}_{2} \mathrm{O}_{3}$ [77]. Likewise, oxides of 1 st row transition metals such as $\mathrm{MnO}_{2}$ $[78,79], \mathrm{Co}_{3} \mathrm{O}_{4}[79,80]$, and lanthanides like $\mathrm{CeO}_{2}[79,81]$ catalyze the $\mathrm{CO} / \mathrm{O}_{2}$ reaction. For $\mathrm{Pt}$, the reaction proceeds with $\mathrm{CO}$ and oxygen, atomic or molecular, chemisorbed on adjacent sites. There are more than one possible catalytic pathways proposed for the reaction over basic oxides: chemisorbed $\mathrm{CO}$ reacts with lattice $\mathrm{O}$ of the oxide metal, then $\mathrm{O}_{2}$ fills in the generated defect site; or alternatively, $\mathrm{CO}$ chemisorbed on an unsaturated metal center and oxygen chemisorbed on a defect site react to produce $\mathrm{CO}_{2}$. Turnovers normalized to metal centers on surfaces and apparent activation energies are quite similar for both metal and oxide type catalysts, indicating identical catalytic behavior among various catalysts for the $\mathrm{CO} / \mathrm{O}_{2}$ reaction [82].

When combined, $\mathrm{Pt}$ and metal oxide composites give rise to orders of magnitude enhancements in catalytic turnovers and lowering of activation energies [83-85]. This invokes either: bi-functional catalysis [86], where different reactants are activated at different catalyst sites and the reaction occurs at the interface between adjacent chemisorption sites; acidbase catalysis, which involves one-way charge transfer from metal to oxide; or some combination of both. As hard as it sounds to devise experiments to isolate the real reaction mechanism, recent in situ studies uncovered a number of previously unknown details to this synergistic chemistry. Colloidally synthesized monodisperse $\mathrm{Pt}$ nanoparticles supported in various metal oxides such as $\mathrm{Co}_{3} \mathrm{O}_{4}, \mathrm{MnO}_{2}$, and $\mathrm{CeO}_{2}$ with controlled physical and structural properties were chosen for this particular study [85]. The composite catalysts were then screened for catalytic oxidation of $\mathrm{CO}$ in both O-rich and CO-rich reaction atmospheres in the $200-250{ }^{\circ} \mathrm{C}$ range. As it will be shown, the Pt/oxide interface gave rise to more than an order of magnitude enhancement in turnovers as compared to pure $\mathrm{Pt}$ (supported in $\mathrm{SiO}_{2}$ ) and pure oxides. The enhancement factor was calculated to be about 1,000 times greater for the $\mathrm{Pt} / \mathrm{Co}_{3} \mathrm{O}_{4}$ catalyst compared to the $\mathrm{Pt} /$ $\mathrm{SiO}_{2}$ catalyst.

In these studies, the Pt/oxide interface is broadly defined and refers to the catalytic synergy achieved as a result of the physical contact made between the metal and oxide. Catalytic turnovers at the Pt/oxide interface were calculated by first subtracting from the overall catalytic conversion the contributions of pure $\mathrm{Pt}$ and pure oxide catalysts and next normalizing with respect to the available Pt surface. Therefore, this method gives a lower bound for interfacial turnovers.

\subsubsection{An Active CoO Phase in Contact with Pt NPS Enhances the CO Oxidation Rates}

Soft X-ray absorption spectroscopy was carried out in a purposely-built gas flow cell [87] by using pelletized nano- 
in situ NEXAFS Measurement

a

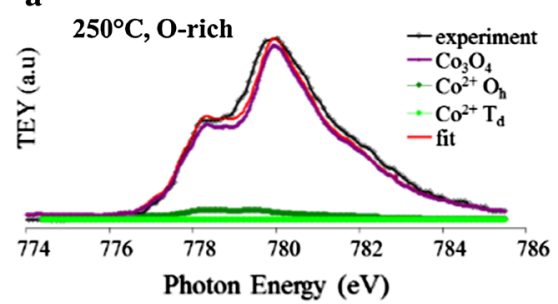

b

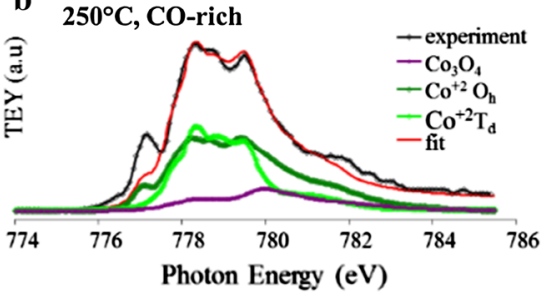

Oxidation States (in situ NEXAFS)

c

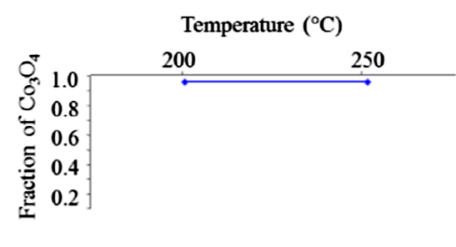

d

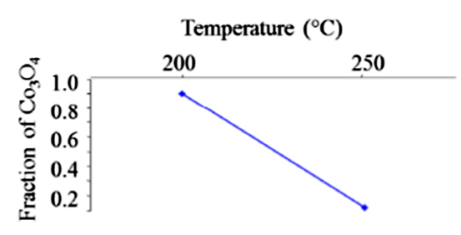

Catalytic Testing

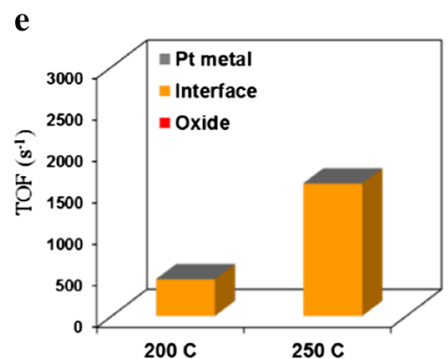

f

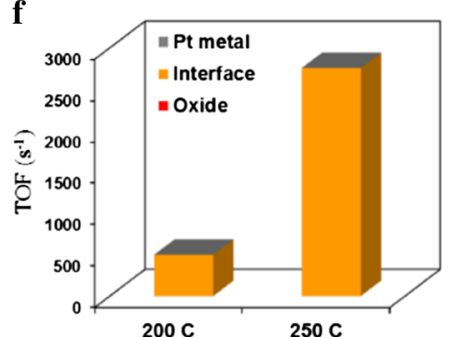

Fig. 6 In situ Co $\mathrm{L}_{3}$ edge NEXAFS spectra measured for the Pt/ $\mathrm{Co}_{3} \mathrm{O}_{4}$ nano-catalyst at $250{ }^{\circ} \mathrm{C}$ and in flowing a O-rich $\left(\mathrm{CO}: \mathrm{O}_{2}, 2: 5\right)$; and $\mathbf{b} \mathrm{CO}$-rich $\left(\mathrm{CO}: \mathrm{O}_{2}, 5: 2\right)$ reaction atmospheres. Oxidation states obtained by least square fitting of the NEXAFS spectra in $\mathbf{c}$ O-rich;

catalysts and identical conditions as the catalytic measurements. It was found that oxide metals were significantly reduced under $\mathrm{CO}$-rich (i.e. net reducing) reaction atmospheres at $250{ }^{\circ} \mathrm{C}$ (Fig. 6a, b). In the case of $\mathrm{Pt} / \mathrm{Co}_{3} \mathrm{O}_{4}$ under $\mathrm{CO}$-rich atmospheres and at $250{ }^{\circ} \mathrm{C}$, the average oxidation state of cobalt determined by a least-square fitting procedure revealed $\mathrm{CoO}$ as by far the majority phase (a fraction of 0.9), while only a small fraction of $\mathrm{Co}_{3} \mathrm{O}_{4}$ was detected (Fig. 6c, d). On the contrary, only a small fraction of $\mathrm{CoO}$ was detected under identical reaction atmosphere at $200{ }^{\circ} \mathrm{C}$ and also under O-rich (i.e. net oxidizing) reaction atmospheres in the $200-250{ }^{\circ} \mathrm{C}$ range. Catalytic turnovers registered for the metal/oxide interface were also identical at $200{ }^{\circ} \mathrm{C}$ for both the $\mathrm{O}$ - and $\mathrm{CO}$-rich reaction atmospheres. However, at $250{ }^{\circ} \mathrm{C}$, where the reduction and phase transformation of cobalt oxide was most pronounced, a two-fold enhancement was obtained under the CO-rich case relative to the O-rich case (Fig. 6e, f). This clearly indicated that the active phase of cobalt oxide was $\mathrm{CoO}$, not $\mathrm{Co}_{3} \mathrm{O}_{4}$, in sharp contrast to the common knowledge in the field prior to this work [88].

In a prior work, colloidally synthesized bimetallic CoPt nanoparticles, having monodisperse $4 \mathrm{~nm}$ sizes and random alloy architectures, were deposited on silicon substrates and studied using in situ soft XAS and catalytic measurements under O-rich (1.4:1 by volume) $\mathrm{CO} / \mathrm{O}_{2}$ reaction atmospheres $\left(0.043-32\right.$ Torr range) and at $125{ }^{\circ} \mathrm{C}$ [87]. It was shown that as-synthesized bimetallic alloy nanoparticles, where $\mathrm{Co}$ and $\mathrm{Pt}$ atoms are randomly and $\mathbf{d}$ CO-rich reaction atmospheres. Catalytic turnovers measured in a plug-flow reactor under $\mathbf{e} \mathrm{O}$-rich; and $\mathbf{f} \mathrm{CO}$-rich conditions [adapted with permission from An et al. [85]. Copyright: (2013) American Chemical Society]

distributed, underwent surface segregation depending on the redox sign of the environment, either catalytically net oxidizing $\mathrm{CO} / \mathrm{O}_{2}$ atmospheres or reducing $\mathrm{H}_{2}$ atmospheres. Co was oxidized to $\mathrm{CoO}$ and diffused to the surface during the $\mathrm{CO} / \mathrm{O}_{2}$ reaction, whereas $\mathrm{Pt}$ segregated to the surface forming Pt-rich layers in net reducing atmospheres. Turnovers were measured and calculated under total $\mathrm{CO} / \mathrm{O}_{2}$ (1.4:1) pressures in the $0.043-32$ Torr range and at $125{ }^{\circ} \mathrm{C}$ by using a batch reactor and the data correlated to fractions of $\mathrm{Co}^{2+}$, as in $\mathrm{CoO}$, obtained under identical conditions. It was shown that a hysteresis existed for both catalytic turnovers and $\mathrm{Co}^{2+}$ fractions when the reactive gas pressures stepwise increased to 32 Torr first and then stepwise decreased back to 0.043 Torr. Therefore, it was concluded that turnovers strongly correlated with the oxidation state of Co beyond the effect of varying chemical potentials over reaction rates. Moreover, when NPs were reduced in $\mathrm{H}_{2}$ prior to dosing the $\mathrm{CO} / \mathrm{O}_{2}$ reaction mixture, the reduction of $\mathrm{Co}^{2+}$ was kinetically induced. This depleted surfaces of catalytically active $\mathrm{CoO}$, causing turnovers to drop significantly and become identical to those of the initial bimetallic alloy NPs (Fig. 7).

The overlapping results of these two works is that $\mathrm{CoO}$ in physical contact with $\mathrm{Pt}$, regardless of how the interface formed (i.e. independent of particle architecture), has promotional effects in the $\mathrm{CO} / \mathrm{O}_{2}$ reaction. One question, however, remained as to whether or not $\mathrm{Co}^{2+}$ centers (or reduced oxide metal sites in general) activate oxygen alone, as bi-functionality would mandate. 


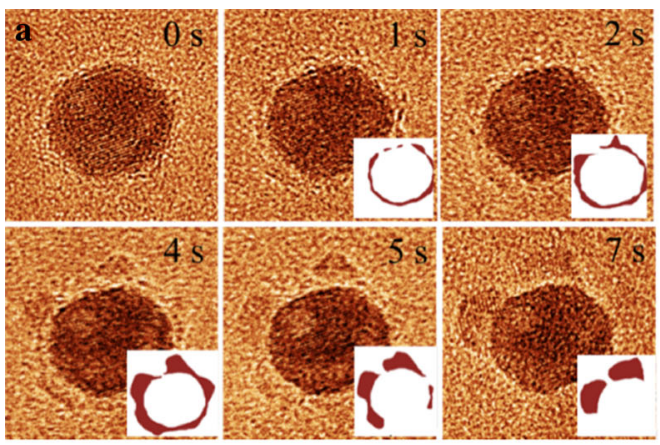

Fig. 7 a ETEM BF time series recorded for a single $10 \mathrm{~nm} \mathrm{CoPt}$ alloy NP in 0.1 Torr $\mathrm{O}_{2}$ and at $250{ }^{\circ} \mathrm{C}$, indicating surface segregation of Co. b Co $\mathrm{L}_{3,2}$ electron energy loss spectra measured for a single alloy NP before and after $\left(\mathrm{O}_{2}\right)$ oxidation. c Co $\mathrm{L}_{3,2}$ electron energy

\subsubsection{O vacancy Sites are not Actively Involved in the Oxidation of $\mathrm{CO}$ at the $\mathrm{Pt} / \mathrm{CeO} \mathrm{O}_{2}$ Interface}

The case of $\mathrm{CeO}_{2}$ is also worth mentioning although it shared the same general tendencies as described above. $\mathrm{CeO}_{2}$ is known to have surface defects in the form of O vacancies [89]. By using a number of synchrotron-based X-ray spectroscopic and diffraction tools in situ, it was shown that Pt decreased substantially the energy barrier for the reduction of $\mathrm{CeO}_{2}$ under $\mathrm{H}_{2}$ atmospheres in the 0.1-150 Torr range and at temperatures between 50 and $350{ }^{\circ} \mathrm{C}$ [90]. It was found that $\mathrm{H}$ atom spillover from the Pt surface onto the $\mathrm{CeO}_{2}$ surface generated $\mathrm{Ce}^{3+}$ and $\mathrm{O}$ vacancies simultaneously. Thus, the surface concentration of $\mathrm{Ce}^{3+}$, generated by $\mathrm{CO}$ from either a direct binding to $\mathrm{CeO}_{2}$ or a spillover at the contact regions with $\mathrm{Pt}$, could be taken as a measure of $\mathrm{O}$ vacancies (Fig. 8a). It was found that the $\mathrm{Pt} / \mathrm{CeO}_{2}$ nano-catalyst was more reduced, producing $\mathrm{Ce}^{3+}$, under $\mathrm{CO}-$ rich atmospheres than O-rich atmospheres at $250{ }^{\circ} \mathrm{C}$ (Fig. 8b). However, the $\mathrm{Pt} / \mathrm{CeO}_{2}$ interface performed better in O-rich reaction atmospheres than in CO-rich reaction atmospheres (Fig. 8c), which indicated the greater involvement of $\mathrm{Ce}^{4+}$ sites rather than $\mathrm{Ce}^{3+}$ sites [85]. It should be noted that this was in sharp contrast with the cases of $\mathrm{Pt} / \mathrm{Co}_{3} \mathrm{O}_{4}$ and $\mathrm{Pt} / \mathrm{MnO}_{2}$ catalysts. Therefore, the $\mathrm{O}$ vacancy sites, because they were found in more abundance when $\mathrm{CeO}_{2}$ was reduced, could not, in principle, facilitate enhanced $\mathrm{CO}$ oxidation rates. This overruled the involvement of lattice defects, specifically $\mathrm{O}$ vacancies, which are the subject matter of the popularly known Mars van Krevelen mechanism [38] for the catalytic oxidation of $\mathrm{CO}$ at the $\mathrm{Pt} / \mathrm{CeO}_{2}$ interface.

\subsubsection{More Oxyphilic Metal Acts as the Oxygen Reservoir for the Oxidation of $\mathrm{CO}$ at the Interface Between Metallic Pt and Metallic Sn}

In a recent work, bimetallic PtSn alloy NPs were compared to pure Pt NPs, with both NPs being monodisperse $(2 \mathrm{~nm})$ and supported on silicon substrates, by using correlative batch
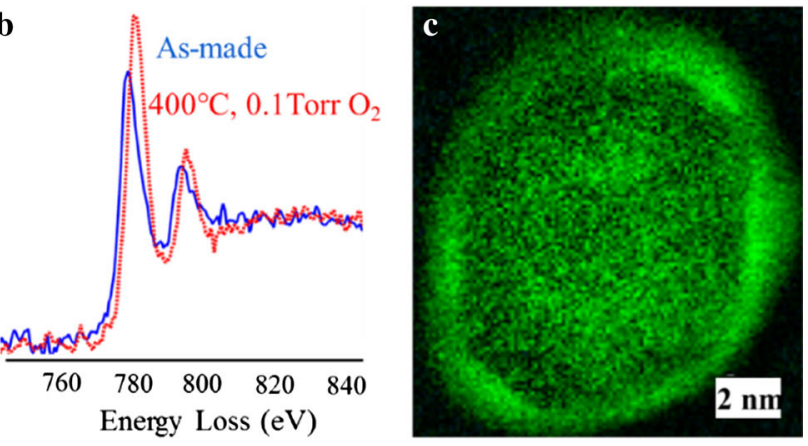

loss map recorded for a single NP after ex situ (air) oxidation at $400{ }^{\circ} \mathrm{C}$, showing $\mathrm{CoO}$ shell [modified with permission from Xin et al. [99]. Copyright: (2014) American Chemical Society]

reactor measurements and APXPS [91]. PtSn NPs exhibited a fourfold drop in activation barrier toward the formation of $\mathrm{CO}_{2}$ for the CO-rich (5:2 by volume) reaction mixture in the 200-300 ${ }^{\circ} \mathrm{C}$ range as compared to pure Pt NPs under identical conditions. Reaction order in $\mathrm{O}_{2}$ was $\sim 0$ in the $40-100$ Torr range and $\sim 0.5$ in the 40-100 mTorr range, the same pressure range as APXPS studies were conducted. The pure $\mathrm{Pt}$ NPs had a reaction order in $\mathrm{O}_{2}$ of approximately 1 .

For the APXPS measurements, photoelectrons with $250 \mathrm{eV}$ kinetic energies, giving inelastic mean free paths on the order of a few layers of the topmost surface, were chosen for both $\mathrm{Pt} 4 \mathrm{f}$ and Sn 3d core levels. Therefore, surface specific information of oxidation states and chemical composition was obtained at the atomic level. The results indicated that the as-synthesized nanoparticles as well as the spent nanoparticles after reduction in $100 \mathrm{mTorr}_{2}$ and at excesses of $350{ }^{\circ} \mathrm{C}$ were randomly mixed alloys, as evidenced by XPS components ascribed to $\mathrm{Pt}(\mathrm{Sn})$ and $\mathrm{Sn}(\mathrm{Pt})$ chemical environments. Under $140 \mathrm{mTorr} \mathrm{CO} / \mathrm{O}_{2}$ (5:2) reaction atmosphere and in the $200-275^{\circ} \mathrm{C}$ range, the alloyed composition changed at the expanse of segregated $\mathrm{Pt}$ and Sn domains. This was followed by a simultaneous oxidation of $\mathrm{Sn}^{0}$ to $\mathrm{Sn}^{2+}$, as in $\mathrm{SnO}$, as shown in Fig. 9. A model was proposed in complete accord with the catalytic and XPS observations: the oxidation of $\mathrm{CO}$ occurred along $\mathrm{CO}$ covered Pt surface boundary in contact with $\mathrm{SnO}$ via the formation of $\mathrm{Sn}^{0}$ and a vacant $\mathrm{Pt}$ site. The vacant site on $\mathrm{Pt}$ was then filled by gas phase diffusion of a $\mathrm{CO}$ molecule or surface diffusion of a chemisorbed $\mathrm{CO}$, while $\mathrm{SnO}$ acted as a reservoir to provide oxygen to the reduced $\mathrm{Sn}^{0}$ sites around the Pt domains.

\section{2 $\mathrm{CO}_{2}$ Hydrogenation over $\mathrm{Co} / \mathrm{TiO}_{2}$ Nano-Composite Catalyst and Bimetallic Co-Pt Nano-Catalysts}

While $\mathrm{O}_{2}$ as an oxidant gauges the redox behavior of the Pt-based catalysts, $\mathrm{H}_{2}$, as a stronger reductant than $\mathrm{CO}$, acts on the oxyphilic metal and high valency metal oxide 
Fig. 8 a In situ Ce $\mathrm{M}_{5,4}$ edge NEXAFS spectra measured at $250{ }^{\circ} \mathrm{C}$ for the $\mathrm{Pt} / \mathrm{CeO}_{2}$ nanocatalyst under O-rich and $\mathrm{CO}$ rich atmospheres. b Fractions of $\mathrm{CeO}_{2}$ obtained by the least square fitting of the NEXAFS spectra in a. c The results of catalytic measurements under O-rich and CO-rich atmospheres and at $250{ }^{\circ} \mathrm{C}$ [Adapted with permission from An et al. [85]. Copyright: (2013) American Chemical Society]
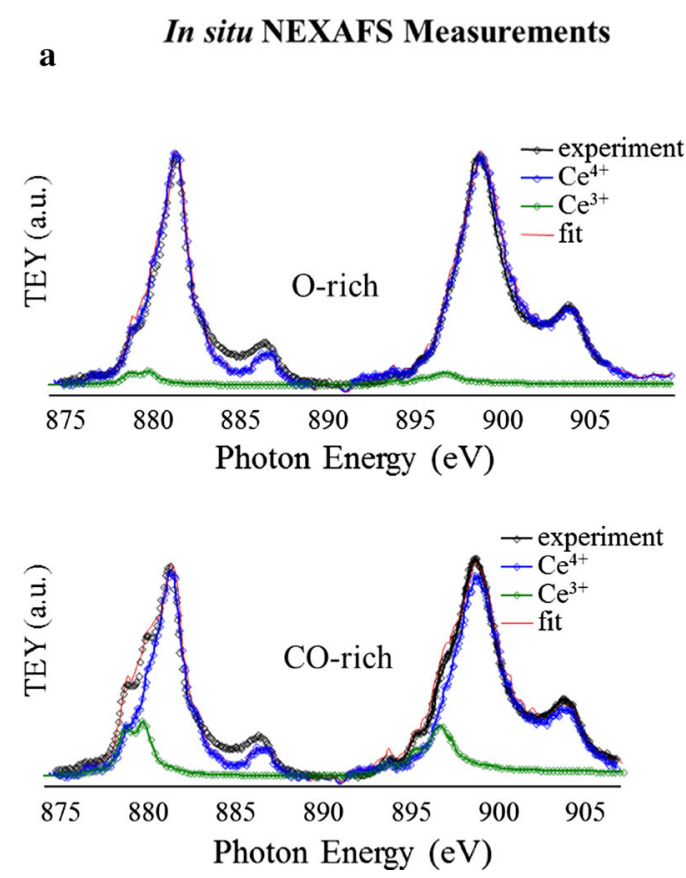

b

\section{Oxidation States}
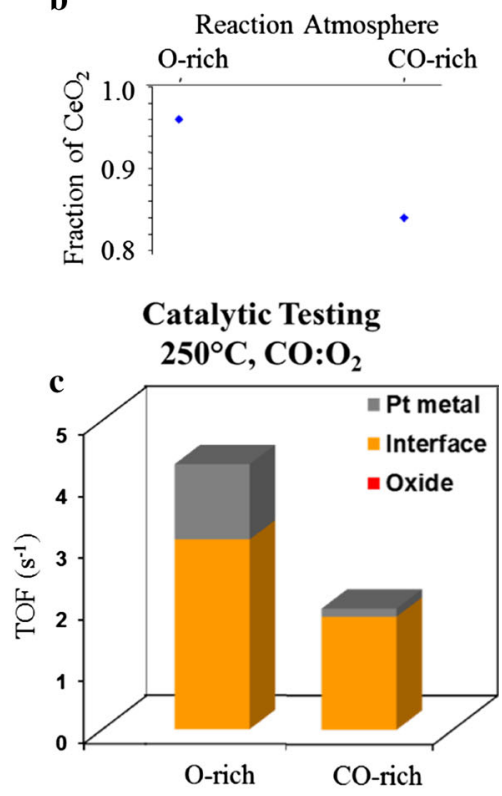

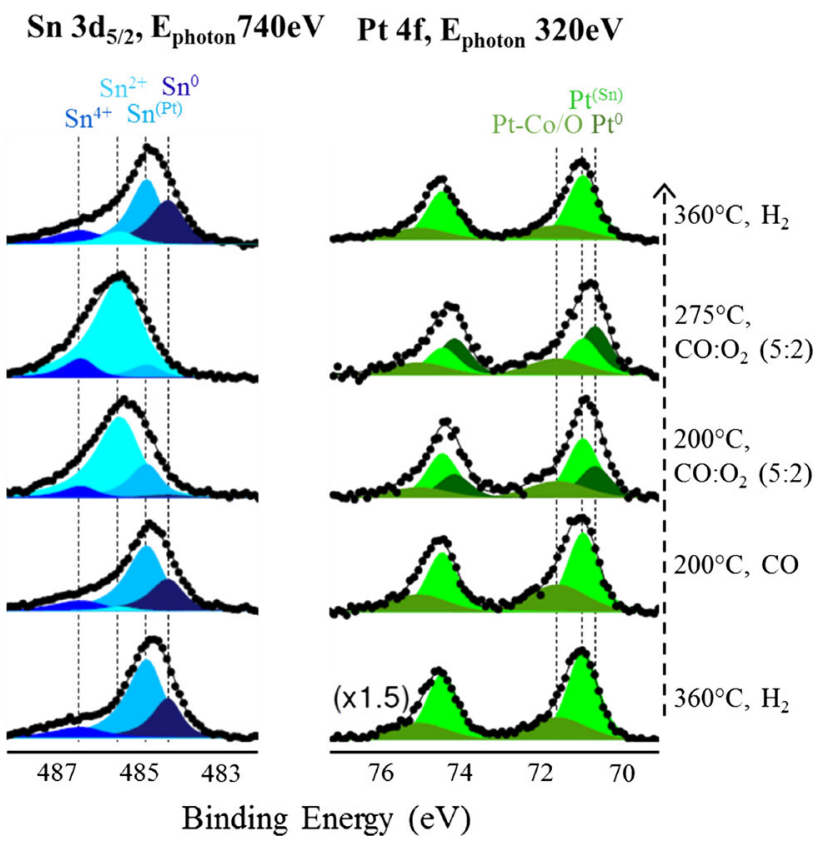

Fig. 9 Sn 3d (left column) and Pt 4f APXPS spectra measured for $2 \mathrm{~nm}$ PtSn alloy NPs in $\mathrm{H}_{2}$ reducing, $\mathrm{CO}$ reducing and two CO-rich reaction atmospheres, indicating reversible changes in the chemical compositions of the topmost surfaces determined by $\sim 250 \mathrm{eV}$ photoelectrons [adapted with permission from Michalak et al. [91]. Copyright: (2014) Journal of Catalysis]

catalysts to alter surface properties and eventually tailor catalytic behavior. Hydrogenative synthesis of olefins, paraffins and oxygenates in the gas and liquid spectrum, from $\mathrm{CO}$, Fischer-Tropsch (F-T), and/or $\mathrm{CO}_{2}$ can be classified in this category.
Co-based catalysts are generally employed for the F-T synthesis. It has been much debated what the active catalyst is. According to one widely accepted model, $\mathrm{CoC}_{x}$ forms upon dissociative adsorption of $\mathrm{CO}$ over metallic $\mathrm{Co}$, and it is this particular $\mathrm{CoC}_{\mathrm{x}}$ phase that catalyzes hydrogenation and carbon chain growth by the insertion of methylene $\left(-\mathrm{CH}_{2}\right)$ groups [92]. When $\mathrm{CO}_{2}$, a mildly oxidizing molecule, is used as a carbon source under a net $\mathrm{H}_{2}$ reducing atmosphere two strongly correlated reaction steps dominate the product distribution: the reverse water gas shift reaction (rWGS), which produces $\mathrm{CO}$ and $\mathrm{H}_{2} \mathrm{O}$; and F-T synthesis that produces $\mathrm{H}_{2} \mathrm{O}, \mathrm{CH}_{4}$ and surface methylene groups, which lead to gas and liquid hydrocarbons [93]. The F-T synthesis is a multi-path/multi-product reaction associated with multi-channel surface diffusion and complex re-adsorption pathways.

Model nano-catalysts under simulated reaction conditions are essential for understanding the catalyst properties and associated catalytic behavior. Size-controlled model Co NPs synthesized by using modified colloidal techniques indicated a weak size dependence (threefold enhancement for larger NPs normalized to surface area) in the 3-10 nm range [8]. It was also found that the reaction was inhibited by phosphorous, residues of one particular colloidal synthesis, present at sub-monolayer coverage, therefore a modified synthetic route, free of phosphorous reagent, was also developed. Furthermore, the gas pressures $\left(4 \mathrm{~atm} \mathrm{H}_{2}: \mathrm{CO}_{2} 3: 1\right)$ and reaction temperatures $\left(200-300{ }^{\circ} \mathrm{C}\right)$ were chosen such as to avoid both complete methanation and chain growth polymerization. By this way, Co nano-catalysts were studied under low conversion and chain growth regimes. 


\subsubsection{Support Effects Over Co NPs Deposited Inside Macroporous $\mathrm{TiO}_{2}$}

In a recent work, $10 \mathrm{~nm}$ monodisperse Co NPs were deposited on mesoporous $\mathrm{SiO}_{2}$ and macroporous $\mathrm{TiO}_{2}$, separately; and the pelletized nano-catalysts were studied under simulated $\mathrm{CO}_{2} / \mathrm{H}_{2}$ conditions by using catalytic measurements and an array of synchrotron based X-ray spectroscopy and diffraction tools [94]. The objective was to capture the more active physical form and chemical state of Co for a given particle size and then to evaluate the support effects, if present. To this end, Co NPs were deliberately oxidized or reduced prior to catalytic testing, and then all steps were monitored by using soft X-ray absorption spectroscopy. It was notable that fully metallic Co, cubic phase, formed upon reduction in 150 Torr $\mathrm{H}_{2}$ at $450{ }^{\circ} \mathrm{C}$. When oxidized in 150 Torr $\mathrm{O}_{2}$ and at $350{ }^{\circ} \mathrm{C}$, metallic $\mathrm{Co}$ was converted to $\mathrm{CoO}$, cubic phase. The $\mathrm{CoO}$ remained oxidized under $\sim 3$ atm of $\mathrm{H}_{2}: \mathrm{CO}_{2}(3: 1)$ at $250{ }^{\circ} \mathrm{C}$. Catalytically, $\mathrm{CoO}$ was superior to metallic $\mathrm{Co}$ by almost 10:1 when supported in $\mathrm{TiO}_{2}$, which rendered the $\mathrm{CoO} / \mathrm{TiO}_{2}$ composite nano-catalyst superior to any such model system studied to date. It was further shown that when deposited on inert $\mathrm{SiO}_{2}$ metallic Co was more active than $\mathrm{CoO}$ by almost threefold, in accord with the general model that identified metallic Co as the initially active state. No spectroscopic or crystallographic evidence was, however, found that could be attributed to a $\mathrm{CoC}_{x}$ phase.

This work further identified enhanced wetting of $\mathrm{CoO}$ on $\mathrm{TiO}_{2}$ as one potential explanation for catalytic promotion of the oxidized state. By using APXPS, it was demonstrated that the topmost surface, corresponding to inelastic mean free paths of $180 \mathrm{eV}$ photoelectrons, of the $\mathrm{CoO}_{x} / \mathrm{TiO}_{2}$ catalyst changed dramatically (Fig. 10a, b). $\mathrm{CoO}_{\mathrm{x}}$ formed when the catalyst was treated in $100 \mathrm{mTorr} \mathrm{O}_{2}$ at $350{ }^{\circ} \mathrm{C}$, and no trace of metallic Co was found when $\mathrm{O}_{2}$ was pumped out and $\mathrm{H}_{2}$ was dosed at $250{ }^{\circ} \mathrm{C}$. Also in $100 \mathrm{mTorr}_{2}$ and $250{ }^{\circ} \mathrm{C}$, $\mathrm{CoO}_{\mathrm{x}}$ occupied more space on the topmost surface regions which was ascribed to wetting of $\mathrm{TiO}_{2}$ by $\mathrm{CoO}_{x}$ (Fig. 10c). When temperature was increased to $450{ }^{\circ} \mathrm{C}$ in 100 mTorr $\mathrm{H}_{2}$, Co was partially reduced. Metallic Co was then encapsulated in part by $\mathrm{TiO}_{2}$, decreasing its surface coverage and interaction with the oxide, probably as a result of the lower surface free energy of the oxide (Fig. 10d). This encapsulation of Co NPs by $\mathrm{TiO}_{2}$ must have been more pronounced under reaction pressures (i.e. more than four orders of magnitude higher in $\mathrm{H}_{2}$ when compared to APXPS) pertinent to soft XAS measurements (and catalytic testing), which detected only metallic $\mathrm{Co}$ in the near surface regions. Therefore, the loss of active catalyst surface and exposed $\mathrm{CoO}_{\mathrm{x}} / \mathrm{TiO}_{2}$ interface, both linked to the encapsulation, must be responsible for the activity drop observed for the reduced catalyst (Fig. 10e, f).

\subsubsection{The Role of Nobler Metal in Co-Based Bimetallic Nano-Catalysts During $\mathrm{CO}_{2}$ Hydrogenation}

Recently, the role of a second metal in Co-based bimetallic catalysts was put into question based on a study using in situ Soft X-ray Spectroscopy and E-TEM [95]. When Co was co-precipitated with a second metal such as Re or Pt the enhanced F-T synthesis activity obtained for the resulting catalyst, usually ill-characterized yet generally assumed to be some alloy form, is attributed to high reducibility of Co [96-98]. In this work, a two-dimensional film of bimetallic CoPt alloy NPs, monodisperse $4 \mathrm{~nm}$ in size and 50:50 compositions, were investigated in redox atmospheres $\left(\mathrm{H}_{2}\right.$ or $\left.\mathrm{O}_{2}\right)$ at temperatures in the $125-250{ }^{\circ} \mathrm{C}$ range. $\mathrm{CoPt}$ NPs performed poorly during catalytic hydrogenation of $\mathrm{CO}_{2}$ and were exclusively selective for the formation of $\mathrm{CO}$ (i.e. active only for the rWGS reaction). The lack of methanation reactivity and the production of CO were consistent with pure Pt NPs screened in a control run. Soft NEXAFS spectroscopy revealed easier reducibility and larger capacity of Co to remain metallic in the alloy nanoparticles compared to pure Co NPs of identical monodisperse sizes, which was attributed to a hydrogen spillover effect. The initial findings supported the generally accepted model for bimetallic F-T catalysts.

However, further investigations over model CoPt NPs using APXPS for $4 \mathrm{~nm}$ sizes and E-TEM for $10 \mathrm{~nm}$ sizes indicated that the reduction of Co was accompanied by the core/shell restructuring of the originally alloy NPs [87]. In the revisited model, $\mathrm{Pt}$ atoms, randomly distributed intraparticle, diffused outward forming thin $\mathrm{Pt}$ shells in $\mathrm{H}_{2}$ atmospheres which facilitated the reduction of Co atoms. In the mTorr $\mathrm{O}_{2}$ pressures, $\mathrm{Pt}$ shells screened subshell Co atoms from oxidation. As the $\mathrm{O}_{2}$ partial pressure increased beyond 100 mTorr, Co was oxidized and substituted Pt on the surface. Likewise, annular dark field images obtained in $100 \mathrm{mTorr}_{2} \mathrm{H}_{2}$, the same partial pressure as in APXPS studies, for individual nanoparticles (Fig. 11), showed bright surface layers and dark subsurface shells, indicating the enrichment of higher $\mathrm{Z} \mathrm{Pt}$ atoms in the surface regions and Co atoms in the subsurface regions [95, 99]. Hence, TEM agreed with the APXPS results pointing to core/shell restructuring and $\mathrm{Pt}$ surface segregation of once alloyed nanoparticles in $\mathrm{H}_{2}$ atmospheres. Catalytically, the bimetallic CoPt NPs then behaved Pt-like as a result of the surface enrichment of $\mathrm{Pt}$ under net reducing atmospheres of the $\mathrm{H}_{2} / \mathrm{CO}_{2}$ reaction.

These in situ findings have implications in the design and fabrication of F-T catalysts. First, the ratios of metal components for bimetallic F-T catalysts, when chosen above the surface-to-volume ratio for any given catalyst particle, render the formation of a full monolayer of the second metal possible. For example, surface to volume 

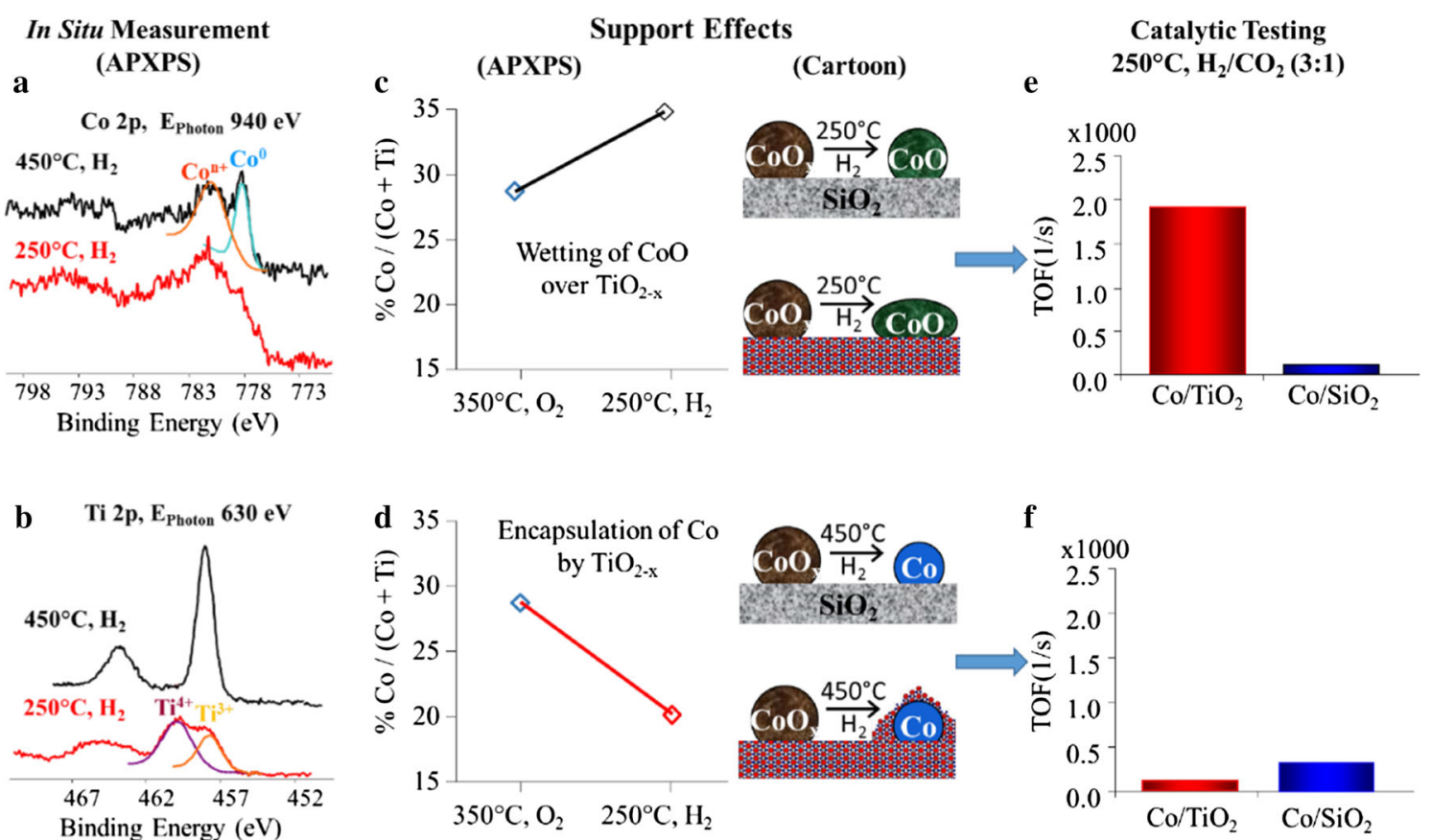

Fig. 10 a Co $2 p$ and b Ti 2p APXPS spectra recorded in 100 mTorr $\mathrm{H}_{2}$ and at given temperatures. \% Co on surface calculated from the APXPS spectra under $\mathrm{H}_{2}$ atmospheres and at c $250{ }^{\circ} \mathrm{C}$ and $\mathbf{d} 450{ }^{\circ} \mathrm{C}$. Cartoon depicts the support effects, comparing $\mathrm{SiO}_{2}$ (i.e. inert) and $\mathrm{TiO}_{2}$ substrates, as deduced from the APXPS results. Turnovers

compare catalytic hydrogenation of $\mathrm{CO}_{2}$ over e oxidized $\mathrm{CoO}$ NPs and $\mathbf{f}$ metallic $\mathrm{Co}$ NPs supported in $\mathrm{SiO}_{2}$ and $\mathrm{TiO}_{2}$. Note that the $\mathrm{y}$-axes are given to the same scales in $\mathbf{c}, \mathbf{d}$ and $\mathbf{e}, \mathbf{f}$ [Adapted with permission from Melaet et al. [94]. Copyright: (2014) American Chemical Society]
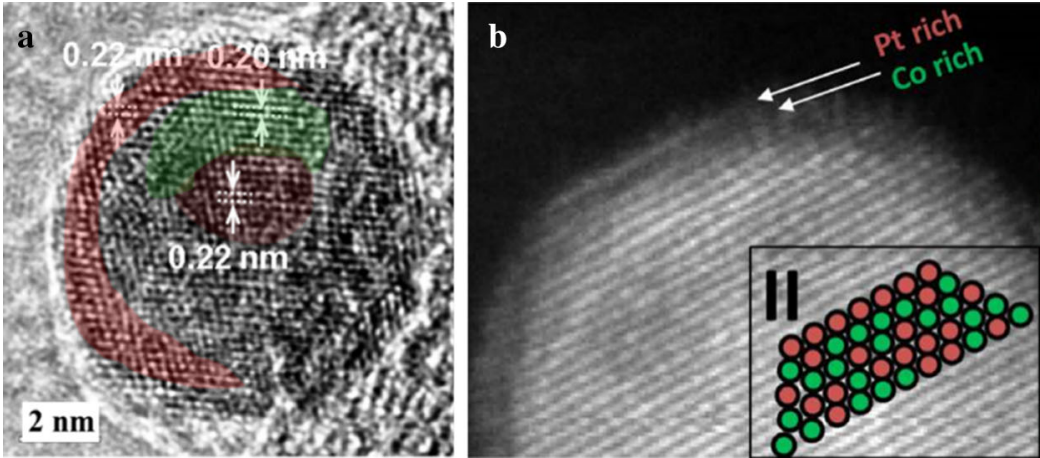

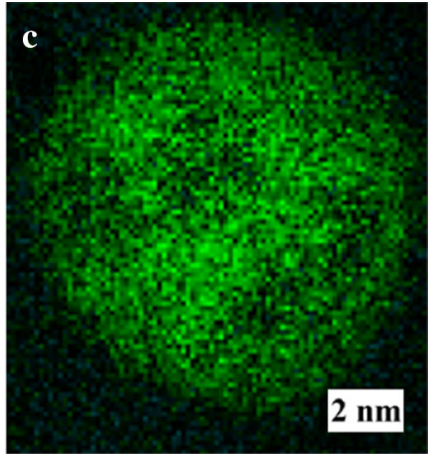

enrichment of Co in the subsurface as expected of the lower Z Co. c Co $\mathrm{L}_{3,2}$ electron energy loss map recorded after $\left(\mathrm{H}_{2}\right)$ reduction at $400{ }^{\circ} \mathrm{C}$. Note that Co shuffled back into the alloy particle as compared to the segregated particle in Fig. 7c [modified with permission from Xin et al. [99]. Copyright: (2014) American Chemical Society]

$\mathrm{Pt}$ - - are kinetically metastable under synthetic F-T conditions, they are subject to core/shell restructuring where noble metal components tend to surface segregate in the thermodynamic limit. This statement is also true for any core/shell architecture with oxyphilic metal atoms comprising the shells. Then, the active particle architecture must have been overlooked; physically mixed composites of the two metal systems could well have been the active form of the bimetallic F-T catalysts. 


\subsubsection{Hydrogen Atom Spillover Between Pt and Co NPs When no Physical Contact was Established Between the Two}

This hypothesis was put to the test in a more recent work. Two model catalyst architectures were fabricated: a mixture of individual monometallic nanoparticles supported within the same physical domain (i.e. a physical mixture); and a mixture of supported nanoparticle domains, each with only one kind of metal (i.e. a mechanical mixture) [100]. Experimentally, monometallic Co and Pt NPs, synthesized with known colloidal procedures, were either: mixed in a 30:1 mol ratio (Co:Pt) before being deposited on mesoporous silica (physical mixture); or deposited separately on mesoporous silica and the supported composites then mixed to give a $30: 1 \mathrm{~mol}$ ratio of $\mathrm{Co}: \mathrm{Pt}$ (mechanical mixture). Catalytically, both the physical and mechanical mixtures of Co and Pt NPs showed more than a fivefold enhancement in turnovers with improved selectivity toward methane formation relative to a pure Co catalyst. In 150 Torr $\mathrm{H}_{2}$ and in the $175-225{ }^{\circ} \mathrm{C}$ range, both catalyst mixtures exhibited larger fractions of metallic Co in the near surface regions, evidenced by in situ NEXAFS studies of the two-dimensional NP films at the Co L edge. As to the topmost surface by extrapolating from the surface-to-volume ratio metallic Co was found only for the $\mathrm{Pt}-\mathrm{Co}$ catalyst mixtures, while the pure Co catalyst was completely oxidized. It was demonstrated that a hydrogen spillover pathway existed for the mixtures regardless of the interparticle separation between Pt and Co NPs. The $\mathrm{H}_{2}$ / $\mathrm{CO}_{2}$ reaction was promoted by increased availability of atomic hydrogen either to remove surface oxides and hydroxides, to be inserted into the carbon backbone, or a combination thereof.

\subsection{Hydrogenation of Unsaturated Hydrocarbons and Hydrogenative Isomerization of Methylcyclopentane}

Hydrogen spillover from Pt NPs onto oxide supports have profound implications in tailoring catalytic selectivity [101]. In situ SFG vibrational spectroscopy (VS) combined with catalytic measurements can help in understanding the hydrogenative reforming reactions which usually exhibit complex reaction networks.

\subsubsection{Hydrogen Atom Spillover at the Pt/TiO Interface During Hydrogenation of Furfural and Crotanaldehyde}

Selective hydrogenation of carbonyl bonds in unsaturated aldehydes to form unsaturated alcohols has been recently demonstrated for $2 \mathrm{~nm}$ Pt NPs supported at a sub-

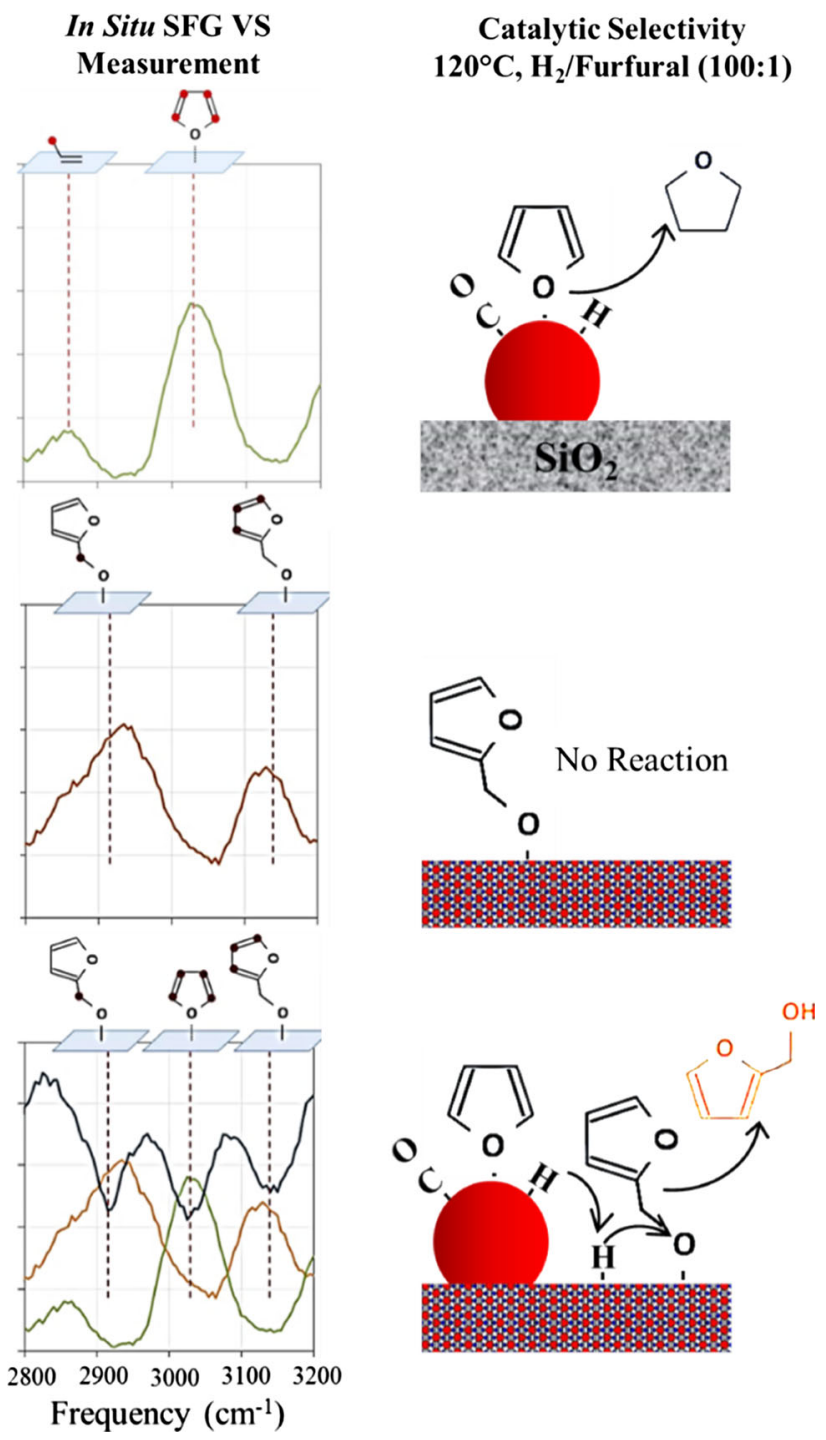

Fig. 12 In situ SFG spectra (left column) obtained in $\mathrm{H}_{2}$ /furfural (100:1) and at $120{ }^{\circ} \mathrm{C}$ for $\mathrm{Pt} / \mathrm{SiO}_{2}, \mathrm{TiO}_{2}$ and $\mathrm{Pt} / \mathrm{TiO}_{2}$ model nanocatalysts (from top to bottom). Cartoons (right column) show the binding geometries of reactants as deduced from the SFG results and major products from catalytic measurements [adapted with permission from Baker et al. [13, 102]. Copyright: (2012) American Chemical Society]

monolayer coverage on e-beam evaporated $\mathrm{TiO}_{2}$ films $(\sim 50 \mathrm{~nm})$ by using in situ SFG VS and catalytic measurements during hydrogenation of furfural [102] and crotanaldehyde [103]. Both molecules were found to produce more unsaturated alcohols (i.e. selective hydrogenation of the carbonyl bond) than saturated alcohols (nonselective hydrogenation of both the carbonyl bond and $\mathrm{C}=\mathrm{C}$ double bond) or unsaturated aldehydes (selective hydrogenation of $\mathrm{C}=\mathrm{C}$ double bond) over a $\mathrm{Pt} / \mathrm{TiO}_{2}$ catalyst when compared to Pt NPs deposited on thermally grown $\mathrm{SiO}_{2}$. It was proposed based on in situ SFG studies under identical conditions as the catalytic testing that unsaturated 
aldehydes chemisorbed on $\mathrm{Pt}$ sites with their $\mathrm{C}=\mathrm{C}$ double bonds lying parallel to the surface while $\mathrm{C}=\mathrm{O}$ bonds were located upright and away from the surface. This bonding configuration led to selective hydrogenation of the $\mathrm{C}=\mathrm{C}$ double bond and desorption of the saturated aldehyde, as illustrated in Fig. 12 for the hydrogenation of furfural. However, $\mathrm{Ti}^{3+}$ centers associated with $\mathrm{O}$ defects on the $\mathrm{TiO}_{2}$ surface acted as unique adsorption sites for the unsaturated aldehydes with their $\mathrm{C}=\mathrm{O}$ bonds facing down and $\mathrm{C}=\mathrm{C}$ double bonds pointing up and away from the surface. In this case, $\mathrm{C}=\mathrm{O}$ bonds were selectively reduced to form alcohols by atomic hydrogen spillover from nearby $\mathrm{Pt} \mathrm{NP}$ surfaces, as shown previously for $\mathrm{Pt} / \mathrm{CeO}_{2}$ and $\mathrm{Pt}-\mathrm{Co}$ hybrid nano-catalysts above.

\subsubsection{Surface Diffusion of Intermediates at the Pt NP Mesoporous Zeolite Interface During Hydrogenative Isomerization of Methylcyclopentane}

Spillover of reactants other than hydrogen was documented for hydrogenative isomerization of methylcyclopentane (MCP) over model Pt/mesoporous zeolite nano-catalysts by using in situ SFG [104]. For this study, $2.5 \mathrm{~nm}$ monodisperse Pt NPs were deposited in mesoporous zeolites of two different crystal framework structures: the BEA zeolite framework with a $\mathrm{Si}: \mathrm{Al}$ ratio of 10 and the MFI zeolite framework with a Si:Al ratio of 1 . Hydrogenative isomerization of methylcyclopentane was carried out in a plugflow reactor using 10 Torr MCP, 50 Torr $\mathrm{H}_{2}$ in a balance of 700 Torr $\mathrm{He}$ at $150{ }^{\circ} \mathrm{C}$. The in situ SFG VS studies were carried out under the same conditions. It was found that both $\mathrm{Pt} /$ zeolite nano-composite catalysts led to ring enlargement pathways, producing cyclohexane and benzene, which were not detected for the $\mathrm{MCP} / \mathrm{H}_{2}$ reaction over either pure $\mathrm{Pt}$ or mesoporous zeolites. It was also noticeable that the Pt/BEA catalyst produced cyclohexane with $\sim 70 \%$ selectivity, while the Pt/MFI catalyst produced benzene with $\sim 80 \%$ selectivity. Furthermore, both catalysts exhibited an order of magnitude enhancement in turnovers normalized to either available Pt sites or zeolitic $\mathrm{Al}$ sites.

SFG spectra indicated for both the Pt/zeolite catalysts the presence of a methylene stretch of saturated $\mathrm{C}_{6}$ cyclics at $2,780 \mathrm{~cm}^{-1}$ and $=\mathrm{CH}_{2}$ asymmetric stretch of unsaturated $\mathrm{C}_{6}$ cyclics at $3,065 \mathrm{~cm}^{-1}$. The vibrational signatures were consistent with those of cyclohexene, and the lack of cyclohexene among the products indicated that it formed as a reactive intermediate on the catalyst surfaces at the interface between the Pt and alumina silicate support. A control run using 10 Torr cyclohexene and 50 Torr $\mathrm{H}_{2}$ in a balance of 700 Torr He led to $\sim 70 \%$ cyclohexane over the Pt/BEA and $\sim 80 \%$ benzene over the Pt/MFI. In addition both the catalysts achieved almost complete conversion, suggesting that if cyclohexene formed it would indeed hydrogenate/dehydrogenate to cyclohexane/benzene. It was proposed that an unsaturated $\mathrm{C}_{6}$ cyclic, most probably cyclohexene, was generated at the interface of the Pt and zeolites which in turn hydrogenated/dehydrogenated to the final products. Furthermore, the ratios of cyclohexene and benzene were governed by the zeolite framework type; BEA with the higher Si:Al ratio led to more hydrogenation (a factor of two) whereas MFI with the lower $\mathrm{Si}$ :Al ratio led to more benzene (a factor of four). SFG spectra displayed physisorbed benzene at $3,035 \mathrm{~cm}^{-1}$ only for the Pt/MFI, in accord with the higher benzene formation rate obtained for this catalyst.

\subsection{Heterogenized Homogeneous Transformations in Organic Solvents}

Re-adsorption contributes to product evolution in cascade catalytic reaction systems, as important a factor as the reactant spillover in other multi-path/multi-product reactions. In this respect, homogeneous hydrocarbon transformations, especially those that involve single metal sites and single reaction centers, are the most fundamental systems to look for. When carried out heterogeneously, homogeneous catalytic reactions can be understood in the surfacereactivity context; however, their kinetic investigation in the heterogeneous mode requires tools with time resolutions in the same regimes as residence times, usually in the millisecond time scale. In Fourier transformed IR where measurements in the vibrational time domain are exchanged for vibrational frequency domain, spectral acquisition can be gated with reactive gases pulsed in short time intervals on the millisecond scale $[105,106]$. Therefore, FTIR can provide the instrumental time resolution necessary to monitor the history, frozen in time, of catalytic transformations. However, such short time scales are not measurable by XAS tools not even when quick XAFS [107] and energy dispersive XAFS [107, 108] techniques are employed.

In a recent work, time-on-stream reaction events in the millisecond time scales were resolved simply by using reactor geometry, reactant flow rate, and micron-sized XAS probes. For this study a capillary quartz tube of $1 \mathrm{~mm}$ diameter was employed where the powder catalyst was packed in a $10 \mathrm{~mm}$ long bed. For a linear flow rate of reactants (v) and any given distance from the origin of the catalyst bed (l), the time-on-stream of reactants is calculated by the equation, $1 / \mathrm{v}$. The time resolution is then obtained by the probe size and flow rate $(0.5 \mathrm{~ms}$ for a $10 \mu \mathrm{m}$ probe and $5 \mathrm{ml} / \mathrm{h}$ flow rate), and the shortest timeon-stream measurable is only limited by the motion of the 

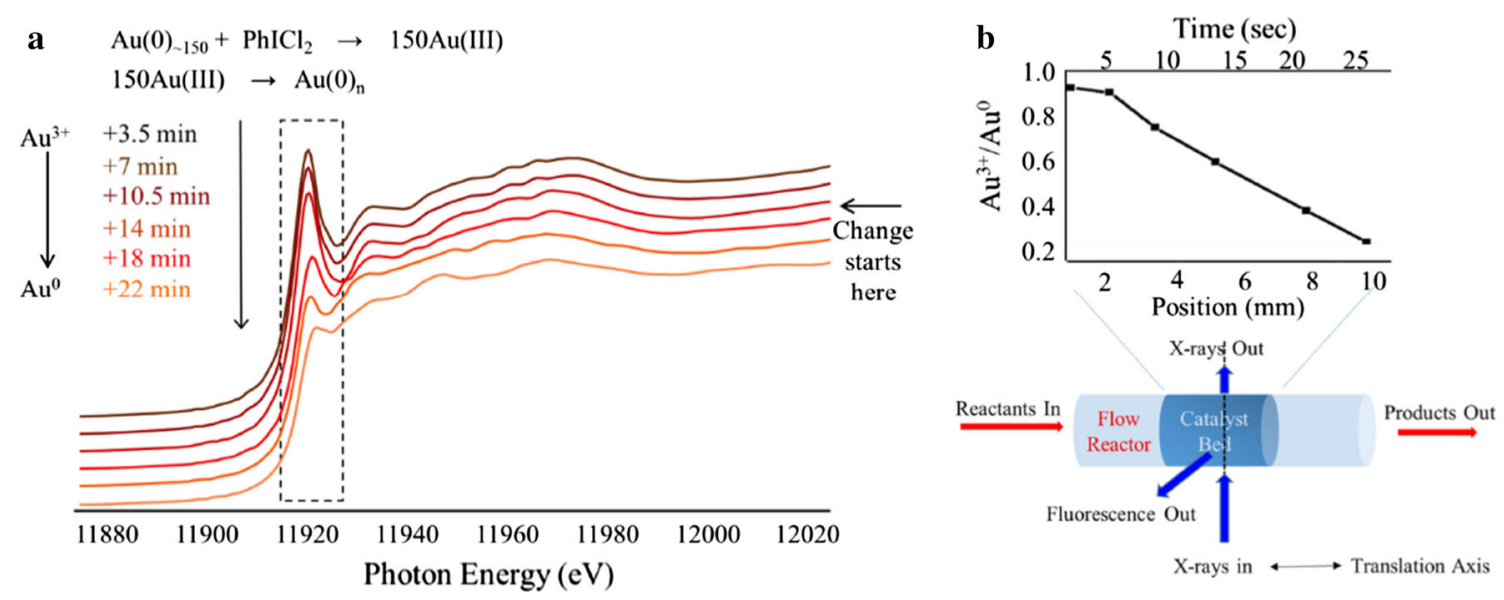

Fig. 13 a Time series of $A u L_{3}$ edge Quick NEXAFS spectra recorded in $3.5 \mathrm{~min}$ intervals (which sets the instrumental resolution) showing the reduction of a $\mathrm{PhICl}_{2}$ oxidized Au nano-catalyst in the batch mode. b Ratios of $\mathrm{Au}^{3+} / \mathrm{Au}^{0}$ calculated from a least squares fitting of the NEXAFS spectra recorded at various positions along a

stepped motor, which is used to translate the probe along the capillary tube or vice versa. When the $\mathrm{X}$-ray probe is locked in a known distance from the origin, the collective memory of the reaction time-on-stream along the reactor bed up to that position will be stamped on the XAS spectrum regardless of the instrumental time resolution of the XAS setup, illustrated in Fig. 13. By way of trading position with time, the time evolution of the catalyst can then be monitored.

\subsubsection{Time-On-Stream Kinetics of $\mathrm{Au}^{3+}$ Reduction During Hydropyran Synthesis}

This 'trading-position-with-time' strategy was exploited to evaluate a silica supported, dendrimer encapsulated Au NP catalyst during a liquid phase hydropyran synthesis reaction [109]. $2 \mathrm{~nm}$ monodisperse Au NPs were oxidized in situ by $\mathrm{PhICl}_{2}$ present in the butanol reaction solution at stoichiometric amounts to Au. XAS displayed metallic $\mathrm{Au}$ without the $\mathrm{PhICl}_{2}$ oxidant. It also displayed $\mathrm{Au}^{3+}$ with the reaction solution within a $2 \mathrm{~mm}$ distance of the reactor bed, which was registered as a reactant time-on-stream of $5 \mathrm{~s}$ (Fig. 13b). Beyond this distance, Au was gradually reduced back to metallic $\mathrm{Au}$ which rendered the catalyst inactive for the cascade transformation. It was found that no $\mathrm{Au}^{3+}$ was present $10 \mathrm{~mm}$ away from the reaction origin. By using IR microscopy and a similar capillary reactor setup (two $\mathrm{CaF}_{2}$ widows separated by a $0.5 \mathrm{~mm}$ thick spacer), it was found for the same reaction solution in D-butanol that the hydropyran was the sole product beyond $1 \mathrm{~mm}$ distance from the reaction origin. Furthermore, D-butanal was observed beyond this distance, suggesting a competitive capillary micro-reactor during the cascade synthesis of hydropyran. Note that the time steps on the order of seconds were achieved by trading position with time for a flow rate of $5 \mathrm{ml} / \mathrm{h}$, while the spectral acquisition times were about 20 min [adapted with permission from Gross et al. [109]. Copyright: (2014) American Chemical Society]

oxidation pathway as to how Au was reduced back to its metallic state.

\section{Summary and Future Challenges}

Colloidal nanoparticle catalysts are attractive model systems to study catalytic reactions. Tailoring physical and chemical properties of metal nanoparticles and oxide supports/co-catalysts offers an intriguing way of controlling catalyst behavior and catalytic trends. In this context, the particle size and architecture of metal nanoparticles can be varied by using colloidal chemistry to gain insight into the catalytic roles of physical and chemical variables of a catalyst. These variables are crystal shape and morphology, oxidation state, coordination, and bonding. Then, welldefined metal nanoparticles can be deposited on the choice of oxide support/co-catalyst to explore well-known support effects.

In situ surface techniques and tools are required to investigate the dynamic changes that nano-catalyst undergo as catalytic reactions occur. In situ NEXAFS TEY probes the oxidation state changes on the near surfaces of metal catalysts and oxide supports. Furthermore, coordination and bonding stem from in situ EXAFS for small nanoparticles and clusters where surface and bulk become one. Likewise, APXPS is elementally and chemically sensitive to composition changes on the near surfaces under catalytically relevant reactant pressures. In situ SFG VS provides complementary adsorbate bonding structure on the immediate surface. Intermediate species can then be inferred. 
When combined with catalytic turnover and selectivity measurements in reactors built in parallel or in-line with the in situ probe setup, these techniques and tools can lead to better understanding of the catalysis and surface phenomena. As a demonstration of this correlative strategy, some case studies from the Somorjai group employing well-defined nano-catalysts of bimetallic and/or metal/ oxide hybrid architectures were described in relation to support effects, surface bifunctionality, diffusion of neutral species, and charge flow. In situ studies unquestionably gave insight into the structural factors that dynamically alter catalyst surfaces. Nevertheless, there emerged other questions that require new techniques and tools to be developed and novel experimental strategies to be devised.

The support effects, on one hand, invoke strong-metalsupport interactions (SMSI) which have undesired connotations of catalyst deactivation and quenching of catalytic reactivity. This was exemplified by the encapsulation of metallic Co by macroporous $\mathrm{TiO}_{2}$, which was experimentally detected using APXPS in $\mathrm{H}_{2}$ atmospheres and during net reducing atmospheres of the $\mathrm{H}_{2}: \mathrm{CO}_{2}$ (3:1) reaction. On the other hand, SMSI is associated with charge transfer phenomenon, where electrons or protons flowing in one direction selectively enhance certain reaction pathways. SMSI is also associated with bi-functionality, where metals and oxides activating different reactants promote catalytic activity by means of synergism. It was previously demonstrated that electrons are generated at the Schottky interface of $\mathrm{Pt}$ and negatively doped $\mathrm{TiO}_{2}$ films due to the $\mathrm{CO} / \mathrm{O}_{2}$ reaction: charge flow through an external circuit was measured and correlated with catalytic turnovers [110, 111]. However, there is no study to date that unequivocally shows the charge flow between metal nanoparticles and metal oxide supports such as to control catalytic reaction channels and/or turnovers. Therefore, purposely designed and fabricated model nano-catalysts are needed in the future to bridge the existing experimental gap.

Bifunctionality is, however, the apparent reason beyond the promotional effects as demonstrated for the $\mathrm{Pt} / \mathrm{meso}-$ porous metal oxide (e.g. $\mathrm{Co}_{3} \mathrm{O}_{4}, \mathrm{MnO}_{2}$ and $\mathrm{CeO}_{2}$ ) catalysts using soft XAS under catalytic $\mathrm{CO}$ oxidation conditions. It is yet not fully conceivable as to how and why some metal oxides perform superior to others. The only physical correlation found was that the redox states (i.e. in situ NEXAFS) of metal oxides respond to the redox power of the reaction atmosphere. However, no trend explains the ordering of the different oxides in terms of the measured catalytic turnovers. Hence, to a first approximation, it could be the oxides' resistance to charge flow. It was believed that surface defects and vacancies, as illustrated for the Pt/ $\mathrm{CeO}_{2}$ catalyst, could act as trap sites for charged species as to mitigate the catalytic enhancement measured. Therefore, metal oxides with well-controlled crystalline phases and defect chemistries are essential to future experiments which should be devised to generalize this unique observation to other metal oxide systems.

Reactant (i.e. neutral species) spillover can be considered in the same category as interfacial charge flow, yet there exist tools in the service of experimentalists like SFG that are best suited for monitoring the diffusion of these mobile adsorbate molecules. An unsaturated $\mathrm{C}_{6}$ cyclic intermediate, ascribed to cyclohexene, was proposed for the hydrogenative isomerization of MCP over the $\mathrm{Pt} / \mathrm{mes}$ oporous zeolite catalysts based on in situ SFG vibrational spectroscopy. Also by using in situ SFG vibrational spectroscopy, selective hydrogenation of carbonyl functional groups at the $\mathrm{Pt} / \mathrm{TiO}_{2}$ interface was traced back to hydrogen atom spillover from the $\mathrm{Pt}$ surface to $\mathrm{Ti}^{3+}$ sites. Likewise, the enhanced reducibility and methanation yield of Co NPs by physically distant Pt NPs, monitored by in situ soft XAS and catalytic measurements, was attributed to hydrogen atom (i) spillover from nearby Pt NPs to silica support and (ii) uptake from the silica support by Co NPs. This study also highlighted surface diffusion and adsorbate mobility as factors that govern selectivity and reaction kinetics. However, direct spectroscopic evidence of mobile hydrogen atoms is yet to be presented, as in the case of charge transfer (i.e. protons or hydrides).

In this context, time transients and kinetics of catalytic transformations should be explored in greater detail in future studies. This involves advancing instrumental time resolution on one hand and implementing strategies to diminish the need for advanced instrumentation on the other. The trading-position-with-time strategy, using micro-reactors and micron sized X-ray probes, is one that gave rise to time steps in the milliseconds regime. This concept was demonstrated by in situ NEXAFS for the timeon-stream reduction of active $\mathrm{Au}^{3+}$ species during a cascade cyclization reaction. When used with gas flows, where typical flow rates are much higher than liquid flows, the same strategy gives time sensitivity high enough to probe time-on-stream events on the order of microseconds. As a result, the flow of charged (i.e. protons) and neutral (i.e. hydrogen atoms) species can be monitored, providing that chemically sensitive tools are available. However, it should be noted that such technical limitations might remain as grand challenges in the face of in situ studies in the future. Taking an otherwise chemically sensitive tool, XPS for example, hydrogen has no photoelectron spectrum, nor does proton (electron) transfer have any spectral signature other than small core-level shifts in fractions of an electron volt, which are usually very difficult to detect even in UHV.

Finally, new instrumental techniques and design strategies are required for in situ studies of catalyst surfaces. One particular technique of interest is ion scattering, which uses 
ionized gas molecules as depth sensitive probes, like low energy ion scattering [112-114]. When reactive gas molecules are employed as probing ion sources, like atom probe microscopy (APM), an atomically resolved layer by layer construction of catalysts can be achieved [115-119]. However, the destructiveness and high vacuum requirements of ion scattering and microscopy techniques are currently detrimental to their use for in situ or in operando experiments and stand as a grand challenge for their developers.

Spectro-microscopy techniques such as TEM/EELS and AFM-Raman, which provide nanometer size local probes with high surface sensitivity, are also worth mentioning. They are technically advanced to such levels that render unique in situ and in operando studies possible. Along these lines, scanning transmission X-ray microscopy (STXM), which bridged the in situ gap between classical X-ray (absorption or photoelectron) spectroscopy and nano-spectroscopy, sets a milestone. Briefly, STXM uses diffraction zone plates and order sorting apertures (state-ofthe-art X-ray optics) to focus monochromatic soft X-rays to spot sizes of about $40 \mathrm{~nm}$. Nanoparticle powders and films deposited over thin silicon nitride membranes are hermetically sealed along with built-in capillary tubes and resistive micro-heaters, which allow atmospheric pressure reactive gases at elevated temperatures in a gas flow cell. Sample motion along the scanning plane is then achieved by using piezo-controlled stepper motors. By this way, elemental mapping at the absorption edge of transition metals and low-Z elements such as $\mathrm{O}$ and $\mathrm{C}$ can be obtained, in a way not much different than STEM/EELS. This has been previously demonstrated under catalytically relevant flow conditions for a Fe-based Fischer-Tropsch catalyst [120]. In the near future, the catalysis field will benefit from the involvement of such spectro-microscopy techniques in in situ/in operando studies.

Acknowledgments Instrument part of this work was funded by the Materials Science Division (MSD) at the Lawrence Berkeley National Laboratory. The research in the MSD; and the user projects in the Advanced Light Source, Molecular Foundry and National Center for Electron Microscopy were supported by the Director, Office of Energy Research, Office of Basic Energy Sciences of the U.S. Department of Energy under Contract DE-AC02-05CH1123.

\section{References}

1. Vanharde R, Hartog F (1969) Statistics of surface atoms and surface sites on metal crystals. Surf Sci 15:189-230. doi:10. 1016/0039-6028(69)90148-4

2. Alivisatos AP (1996) Perspectives on the physical chemistry of semiconductor nanocrystals. J Phys Chem 100:13226-13239. doi:10.1021/jp9535506

3. El-Sayed MA (2004) Small is different: shape-, size-, and composition-dependent properties of some colloidal semiconductor nanocrystals. Acc Chem Res 37:326-333. doi:10. 1021/ar020204f

4. Mavrikakis M, Hammer B, Norskov JK (1998) Effect of strain on the reactivity of metal surfaces. Phys Rev Lett 81:2819-2822. doi:10.1103/PhysRevLett.81.2819

5. Hammer B, Norskov JK (1995) Electronic factors determining the reactivity of metal surfaces. Surf Sci 343:211-220. doi:10. 1016/0039-6028(96)80007-0

6. Greeley J, Mavrikakis M (2004) Alloy catalysts designed from first principles. Nat Mater 3:810-815. doi:10.1038/ nmat 1223

7. Alayoglu S, Nilekar AU, Mavrikakis M, Eichhorn B (2008) RuPt core-shell nanoparticles for preferential oxidation of carbon monoxide in hydrogen. Nat Mater 7:333-338. doi:10.1038/ nmat2156

8. Iablokov V, Beaumont SK, Alayoglu S et al (2012) Size-controlled model Co nanoparticle catalysts for $\mathrm{CO}_{2}$ hydrogenation: synthesis, characterization, and catalytic reactions. Nano Lett 12:3091-3096. doi:10.1021/n1300973b

9. La Parola V, Kantcheva M, Milanova M, Venezia AM (2013) Structure control of silica-supported mono and bimetallic $\mathrm{Au}-\mathrm{Pt}$ catalysts via mercapto capping synthesis. J Catal 298:170-178. doi:10.1016/j.jcat.2012.11.007

10. Li Y, El-Sayed MA (2001) The effect of stabilizers on the catalytic activity and stability of Pd colloidal nanoparticles in the Suzuki reactions in aqueous solution. J Phys Chem B 105:8938-8943. doi:10.1021/jp010904m

11. Kuhn JN, Tsung C-K, Huang W, Somorjai GA (2009) Effect of organic capping layers over monodisperse platinum nanoparticles upon activity for ethylene hydrogenation and carbon monoxide oxidation. J Catal 265:209-215. doi:10.1016/j.jcat.2009. 05.001

12. Sapi A, Thompson C, Wang Het al (2014) Recovery of Pt surfaces for ethylene hydrogenation-based active site determination. Catal Lett 144:1151-1158. doi:10.1007/s10562-014-1272-y

13. Baker LR, Kennedy G, Krier JM et al (2012) The role of an organic cap in nanoparticle catalysis: reversible restructuring of carbonaceous material controls catalytic activity of platinum nanoparticles for ethylene hydrogenation and methanol oxidation. Catal Lett 142:1286-1294. doi:10.1007/s10562-012-0904-3

14. Alayoglu S, Aliaga C, Sprung C, Somorjai GA (2011) Size and shape dependence on Pt nanoparticles for the methylcyclopentane/hydrogen ring opening/ring enlargement reaction. Catal Lett 141:914-924. doi:10.1007/s10562-011-0647-6

15. Akguel G, Aksoy F, Bozduman A et al (2008) Study of the L-2, L-3 edges of $3 \mathrm{~d}$ transition metals by X-ray absorption spectroscopy. Thin Solid Films 517:1000-1004. doi:10.1016/j.tsf. 2008.08.173

16. Solomon J, Madix R, Stohr J (1988) Pi-bonded intermediates in alcohol oxidation-orientations of allyloxy and propargyloxy on $\operatorname{Ag}(110)$ by near edge X-ray absorption fine-structure. J Chem Phys 89:5316-5322. doi:10.1063/1.455622

17. Hoffmann H, Zaera F, Ormerod R et al (1992) A near-edge $\mathrm{X}$-ray absorption fine-structure and photoelectron spectroscopic study of the structure of acetylene on $\operatorname{Pd}(111)$ at low-temperature. Surf Sci 268:1-10. doi:10.1016/0039-6028(92)90945-3

18. Nagasaka M, Nakai I, Kondoh H et al (2003) Oxygen K-edge near edge X-ray absorption fine structures of $\mathrm{O}$ and $\mathrm{OH}$ overlayers on $\mathrm{Pt}(111)$. Chem Phys Lett 375:419-424. doi:10.1016/ S0009-2614(03)00876-5

19. Nashner MS, Frenkel AI, Somerville D et al (1998) Core shell inversion during nucleation and growth of bimetallic $\mathrm{Pt} / \mathrm{Ru}$ nanoparticles. J Am Chem Soc 120:8093-8101. doi:10.1021/ ja980638z

20. Frenkel AI, van Bokhoven JA (2014) X-ray spectroscopy for chemical and energy sciences: the case of heterogeneous 
catalysis. J Synchrotron Radiat 21:1084-1089. doi:10.1107/ S1600577514014854

21. Liu H, Guo J, Yin Y et al (2007) Electronic structure of cobalt nanocrystals suspended in liquid. Nano Lett 7:1919-1922. doi: $10.1021 / \mathrm{nl} 0705860$

22. Knop-Gericke A, Havecker M, Schedel-Niedrig T, Schlogl R (2000) High-pressure low-energy XAS: a new tool for probing reacting surfaces of heterogeneous catalysts. Top Catal 10:187-198

23. Mayer RW, Havecker M, Knop-Gericke A, Schlogl R (2001) Investigation of ammonia oxidation over copper with in situ NEXAFS in the soft X-ray range: influence of pressure on the catalyst performance. Catal Lett 74:115-119. doi:10.1023/A: 1016640128384

24. Herranz T, Deng X, Cabot A et al (2009) Influence of the cobalt particle size in the $\mathrm{CO}$ hydrogenation reaction studied by in situ X-ray absorption spectroscopy. J Phys Chem B 113:10721-10727. doi:10.1021/jp901602s

25. Zheng F, Alayoglu S, Guo J et al (2011) In situ x-ray absorption study of evolution of oxidation states and structure of cobalt in $\mathrm{Co}$ and $\mathrm{CoPt}$ bimetallic nanoparticles $(4 \mathrm{~nm})$ under reducing $(\mathrm{H} 2)$ and oxidizing $(\mathrm{O} 2)$ environments. Nano Lett 11:847-853. doi:10.1021/nl104209c

26. Escudero C, Jiang P, Pach E et al (2013) A reaction cell with sample laser heating for in situ soft X-ray absorption spectroscopy studies under environmental conditions. J Synchrotron Radiat 20:504-508. doi:10.1107/S0909049513002434

27. Ogletree DF, Bluhm H, Lebedev G et al (2002) A differentially pumped electrostatic lens system for photoemission studies in the millibar range. Rev Sci Instrum 73:3872-3877. doi:10.1063/ 1.1512336

28. Bluhm H (2010) Photoelectron spectroscopy of surfaces under humid conditions. J Electron Spectrosc Relat Phenom 177:71-84. doi:10.1016/j.elspec.2009.08.006

29. Tao F, Grass ME, Zhang Y et al (2008) Reaction-driven restructuring of Rh-Pd and Pt-Pd core-shell nanoparticles. Science 322:932-934. doi:10.1126/science. 1164170

30. Crumlin EJ, Bluhm H, Liu Z (2013) In situ investigation of electrochemical devices using ambient pressure photoelectron spectroscopy. J Electron Spectrosc Relat Phenom 190:84-92. doi:10.1016/j.elspec.2013.03.002

31. Rupprechter G (2007) A surface science approach to ambient pressure catalytic reactions. Catal Today 126:3-17. doi:10.1016/ j.cattod.2006.12.005

32. Gao F, Wood TE, Goodman DW (2010) The effects of water on $\mathrm{CO}$ oxidation over $\mathrm{TiO}_{2}$ supported Au catalysts. Catal Lett 134:9-12. doi:10.1007/s10562-009-0224-4

33. Yao Y, Yan Z, Chen L et al (2012) Nickel particle size effects on cyclohexane dehydrogenation: a combined reaction kinetics and surface science study. Catal Lett 142:1437-1444. doi:10. 1007/s10562-012-0925-y

34. Blaudez D, Buffeteau T, Cornut J et al (1993) Polarizationmodulated Ft-Ir spectroscopy of a spread monolayer at the airwater-interface. Appl Spectrosc 47:869-874. doi:10.1366/ 0003702934415273

35. York RL, Li Y, Holinga GJ, Somorjai GA (2009) Sum frequency generation vibrational spectra: the influence of experimental geometry for an absorptive medium or media. J Phys Chem A 113:2768-2774. doi:10.1021/jp808629r

36. Aliaga C, Tsung C-K, Alayoglu S et al (2011) Sum frequency generation vibrational spectroscopy and kinetic study of 2-methylfuran and 2,5-dimethylfuran hydrogenation over $7 \mathrm{~nm}$ platinum cubic nanoparticles. J Phys Chem C 115:8104-8109. doi:10.1021/jp111343j

37. Baldelli S, Markovic N, Ross P et al (1999) Sum frequency generation of $\mathrm{CO}$ on (111) and polycrystalline platinum electrode surfaces: evidence for SFG invisible surface CO. J Phys Chem B 103:8920-8925. doi:10.1021/jp991649x

38. Rupprechter G, Freund HJ (2001) Adsorbate-induced restructuring and pressure-dependent adsorption on metal nanoparticles studied by electron microscopy and sum frequency generation spectroscopy. Top Catal 14:3-14

39. Somorjai GA, Hwang KS, Parker JS (2003) Restructuring of hydrogenation metal catalysts under the influence of $\mathrm{CO}$ and H-2. Top Catal 26:87-99. doi:10.1023/B:TOCA.0000012989. 45993.6d

40. Somorjai GA, York RL, Butcher D, Park JY (2007) The evolution of model catalytic systems; studies of structure, bonding and dynamics from single crystal metal surfaces to nanoparticles, and from low pressure $\left(<10^{-3}\right.$ Torr) to high pressure $\left(>10^{-3}\right.$ Torr) to liquid interfaces. Phys Chem Chem Phys 9:3500-3513. doi:10. 1039/b618805b

41. Kliewer CJ, Aliaga C, Bieri M et al (2010) Furan hydrogenation over $\mathrm{Pt}(111)$ and $\mathrm{Pt}(100)$ single-crystal surfaces and $\mathrm{Pt}$ nanoparticles from 1 to $7 \mathrm{~nm}$ : a kinetic and sum frequency generation vibrational spectroscopy study. J Am Chem Soc 132:13088-13095. doi:10.1021/ja105800z

42. Tsung C-K, Kuhn JN, Huang W et al (2009) Sub-10 nm platinum nanocrystals with size and shape control: catalytic study for ethylene and pyrrole hydrogenation. J Am Chem Soc 131:5816-5822. doi:10.1021/ja809936n

43. Aliaga C, Park JY, Yamada Y et al (2009) Sum frequency generation and catalytic reaction studies of the removal of organic capping agents from Pt nanoparticles by UV-ozone treatment. J Phys Chem C 113:6150-6155. doi:10.1021/jp8108946

44. Payen E, Dhamelincourt M, Dhamelincourt Pet al (1982) Study of $\mathrm{Co}($ or Ni)-Mo oxide phase-transformation and hydrodesulfurization catalysts by Raman micro-probe equipped with new cells. Appl Spectrosc 36:30-37. doi:10.1366/0003702824638953

45. Heck KN, Janesko BG, Scuseria GE et al (2008) Observing metalcatalyzed chemical reactions in situ using surface-enhanced Raman spectroscopy on $\mathrm{Pd}-\mathrm{Au}$ nanoshells. J Am Chem Soc 130:16592-16600. doi:10.1021/ja803556k

46. Millar G, Metson J, Bowmaker G, Cooney R (1995) In-situ Raman studies of the selective oxidation of methanol to formaldehyde and ethene to ethylene-oxide on a polycrystalline silver catalyst. J Chem Soc Faraday Trans 91:4149-4159. doi:10. 1039/ft9959104149

47. Boghosian S, Bebelis S, Vayenas C, Papatheodorou G (1989) Insitu high-temperature Sers study of Ag catalysts and electrodes during ethylene epoxidation. J Catal 117:561-565. doi:10.1016/0021-9517(89)90366-7

48. Petersen P, Krasser W (1996) Surface enhanced Raman scattering from a ternary catalyst $\mathrm{Cu} / \mathrm{ZnO} / \mathrm{Al}_{2} \mathrm{O}_{3}$ under reaction conditions. Appl Surf Sci 103:91-100. doi:10.1016/0169-4332(96)00472-2

49. Williams CT, Tolia AA, Chan HYH et al (1996) Surfaceenhanced Raman spectroscopy as an in situ real-time probe of catalytic mechanisms at high gas pressures: The CO-NO reaction on platinum and palladium. J Catal 163:63-76. doi:10.1006/ jcat.1996.0305

50. Tolia A, Williams C, Takoudis C, Weaver M (1995) Surfaceenhanced raman-spectroscopy as an in-situ real-time probe of catalytic mechanisms at high gas-pressures: the Co-No reaction on rhodium. J Phys Chem 99:4599-4608. doi:10.1021/j100013a034

51. Williams CT, Black CA, Weaver MJ, Takoudis CG (1997) Adsorption and hydrogenation of carbon monoxide on polycrystalline rhodium at high gas pressures. J Phys Chem B 101:2874-2883. doi:10.1021/jp963429e

52. Otto A, Mrozek I, Grabhorn H, Akemann W (1992) Surfaceenhanced Raman-scattering. J Phys-Condens Matter 4:1143-1212. doi:10.1088/0953-8984/4/5/001 
53. Willets KA, Van Duyne RP (2007) Localized surface plasmon resonance spectroscopy and sensing. Annu Rev Phys Chem $58: 267-297$

54. Xia YN, Halas NJ (2005) Shape-controlled synthesis and surface plasmonic properties of metallic nanostructures. MRS Bull 30:338-344. doi:10.1557/mrs2005.96

55. Lojewska J, Knapik A, Kolodziej A, Jodlowski P (2013) Far field combined AFM and micro-Raman imaging for characterisation of surface of structured catalysts: example of Pd doped $\mathrm{CoO}_{x}$ catalysts on precalcined Kanthal steel. Top Catal 56:1088-1095. doi:10.1007/s11244-013-0074-6

56. Van Schrojenstein Lantman EM, Deckert-Gaudig T, Mank AJG et al (2012) Catalytic processes monitored at the nanoscale with tip-enhanced Raman spectroscopy. Nat Nanotechnol 7:583-586. doi:10.1038/NNANO.2012.131

57. Kneipp K, Wang Y, Kneipp H et al (1997) Single molecule detection using surface-enhanced Raman scattering (SERS). Phys Rev Lett 78:1667-1670. doi:10.1103/PhysRevLett.78.1667

58. Smith J, Thrower P, Vannice M (1981) Characterization of Ni$\mathrm{TiO}_{2}$ Catalysts by Tem, X-ray-diffraction, and chemisorption techniques. J Catal 68:270-285. doi:10.1016/00219517(81)90097-X

59. Schumacher B, Plzak V, Kinne M, Behm RJ (2003) Highly active $\mathrm{Au} / \mathrm{TiO}_{2}$ catalysts for low-temperature $\mathrm{CO}$ oxidation: preparation, conditioning and stability. Catal Lett 89:109-114. doi:10.1023/A:1024731812974

60. Lin Y, Finke R (1994) A more general-approach to distinguishing homogeneous from heterogeneous catalysis: discovery of polyoxoanion-Stabilized and $\mathrm{Bu}(4) \mathrm{n}(+)$-stabilized, isolable and redissolvable, high-reactivity Ir-approximate-to-190-450 nanocluster catalysts. Inorg Chem 33:4891-4910. doi:10.1021/ ic00100a012

61. Klein S, Martens JA, Parton R et al (1996) Amorphous microporous mixed oxides as selective redox catalysts. Catal Lett 38:209-214. doi:10.1007/BF00806570

62. Mehta S, Simmons G, Klier K, Herman R (1979) Catalytic synthesis of methanol from Co-H2. 2. Electron-microscopy (TEM, STEM, micro-diffraction, and energy dispersive analysis) of the $\mathrm{Cu}-\mathrm{ZnO}$ and $\mathrm{Cu}-\mathrm{ZnO}-\mathrm{Cr}_{2} \mathrm{O}_{3}$ catalysts. J Catal 57:339-360. doi:10.1016/0021-9517(79)90001-0

63. Hayashi T, Tanaka K, Haruta M (1998) Selective vapor-phase epoxidation of propylene over $\mathrm{Au} / \mathrm{TiO}_{2}$ catalysts in the presence of oxygen and hydrogen. J Catal 178:566-575. doi:10.1006/jcat. 1998.2157

64. Williams DB, Carter CB (2009) The Transmission Electron Microscope. Springer, New York, pp 3-22

65. Kisielowski C, Freitag B, Bischoff M et al (2008) Detection of single atoms and buried defects in three dimensions by aberration-corrected electron microscope with 0.5-angstrom information limit. Microsc Microanal 14:469-477. doi:10.1017/ S1431927608080902

66. Erni R, Rossell MD, Kisielowski C, Dahmen U (2009) Atomicresolution Imaging with a sub-50-pm electron probe. Phys Rev Lett 102:096101. doi:10.1103/PhysRevLett.102.096101

67. Gai PL, Montero JM, Lee AF et al (2009) In situ aberration corrected-transmission electron microscopy of magnesium oxide nanocatalysts for biodiesels. Catal Lett 132:182-188. doi:10. 1007/s10562-009-0085-x

68. Borodko Y, Ercius P, Pushkarev V et al (2012) From single Pt atoms to Pt nanocrystals: photoreduction of $\mathrm{Pt}^{2+}$ inside of a PAMAM dendrimer. J Phys Chem Lett 3:236-241. doi:10.1021/ jz201599u

69. Barton B, Jiang B, Song C et al (2012) Atomic resolution phase contrast imaging and in-line holography using variable voltage and dose rate. Microsc Microanal 18:982-994. doi:10.1017/ S1431927612001213
70. Zheng H, Sadtler B, Habenicht C et al (2013) Controlling electron beam-induced structure modifications and cation exchange in cadmium sulfide-copper sulfide heterostructured nanorods. Ultramicroscopy 134:207-213. doi:10.1016/j.ultra mic.2013.05.004

71. Egerton RF (2011) Electron energy-loss spectroscopy in the electron microscope, 3rd edn. Springer, pp 22, 206-220, and 362-378

72. Decrescenzi M (1985) Extended energy-loss fine-structures (EELFS): a new structural probe for surfaces and interfaces. Surf Sci 162:838-846. doi:10.1016/0039-6028(85)90987-2

73. Boyes ED, Gai PL (1997) Environmental high resolution electron microscopy and applications to chemical science. Ultramicroscopy 67:219-232. doi:10.1016/S0304-3991(96)00099-X

74. Fuchs S, Hahn T, Lintz H (1994) The Oxidation of carbonmonoxide by oxygen over platinum, palladium and rhodium catalysts from $10^{-10}$ to 1-Bar. Chem Eng Process 33:363-369. doi:10.1016/0255-2701(94)02007-8

75. Gracia FJ, Bollmann L, Wolf EE et al (2003) In situ FTIR, EXAFS, and activity studies of the effect of crystallite size on silica-supported Pt oxidation catalysts. J Catal 220:382-391. doi:10.1016/S0021-9517(03)00296-3

76. Herskowitz M, Holliday R, Cutlip M, Kenney C (1982) Effect of metal dispersion in Co oxidation on supported Pt catalysts. J Catal 74:408-410. doi:10.1016/0021-9517(82)90046-X

77. Allian AD, Takanabe K, Fujdala KL et al (2011) Chemisorption of $\mathrm{CO}$ and mechanism of $\mathrm{CO}$ oxidation on supported platinum nanoclusters. J Am Chem Soc 133:4498-4517. doi:10.1021/ja110073u

78. Liang S, Bulgan FTG, Zong R, Zhu Y (2008) Effect of phase structure of $\mathrm{MnO}_{2}$ nanorod catalyst on the activity for. J Phys Chem C 112:5307-5315. doi:10.1021/jp0774995

79. Ren Y, Ma Z, Qian L et al (2009) Ordered crystalline mesoporous oxides as catalysts for $\mathrm{CO}$ oxidation. Catal Lett 131:146-154. doi:10.1007/s10562-009-9931-0

80. Haruta M, Tsubota S, Kobayashi T et al (1993) Low-temperature oxidation of Co over gold supported on $\mathrm{TiO}_{2}, \mathrm{Alpha}-\mathrm{Fe}_{2} \mathrm{O}_{3}$, and $\mathrm{Co}_{3} \mathrm{O}_{4}$. J Catal 144:175-192. doi:10.1006/jcat.1993.1322

81. Naydenov A, Stoyanova R, Mehandjiev D (1995) Ozone decomposition and Co oxidation on $\mathrm{CeO}_{2}$. J Mol Catal Chem 98:9-14. doi:10.1016/1381-1169(94)00060-3

82. Royer S, Duprez D (2011) Catalytic oxidation of carbon monoxide over transition metal oxides. Chemcatchem 3:24-65. doi: $10.1002 /$ cctc. 201000378

83. Gardner S, Hoflund G, Schryer D et al (1991) Catalytic behavior of noble-metal reducible oxide materials for low-temperature $\mathrm{Co}$ oxidation. 1. Comparison of catalyst performance. Langmuir 7:2135-2139. doi:10.1021/la00058a027

84. Thormahlen P, Skoglundh M, Fridell E, Andersson B (1999) Low-temperature $\mathrm{CO}$ oxidation over platinum and cobalt oxide catalysts. J Catal 188:300-310. doi:10.1006/jcat.1999.2665

85. An K, Alayoglu S, Musselwhite N et al (2013) Enhanced CO oxidation rates at the interface of mesoporous oxides and $\mathrm{Pt}$ nanoparticles. J Am Chem Soc 135:16689-16696. doi:10.1021/ ja4088743

86. Bunluesin T, Gorte RJ, Graham GW (1998) Studies of the water-gas-shift reaction on ceria-supported $\mathrm{Pt}, \mathrm{Pd}$, and $\mathrm{Rh}$ : implications for oxygen-storage properties. Appl Catal B 15:107-114. doi:10.1016/S0926-3373(97)00040-4

87. Zheng F, Alayoglu S, Pushkarev VV et al (2012) In situ study of oxidation states and structure of $4 \mathrm{~nm} \mathrm{CoPt}$ bimetallic nanoparticles during $\mathrm{CO}$ oxidation using $\mathrm{X}$-ray spectroscopies in comparison with reaction turnover frequency. Catal Today 182:54-59. doi:10.1016/j.cattod.2011.10.009

88. Xie X, Li Y, Liu Z-Q et al (2009) Low-temperature oxidation of $\mathrm{CO}$ catalysed by $\mathrm{Co} 3 \mathrm{O} 4$ nanorods. Nature 458:746-749. doi:10. 1038/nature07877 
89. Mogensen M, Sammes NM, Tompsett GA (2000) Physical, chemical and electrochemical properties of pure and doped ceria. Solid State Ion 129:63-94. doi:10.1016/S0167-2738(99)00318-5

90. Alayoglu S, An K, Melaet G et al (2013) Pt-Mediated Reversible Reduction and Expansion of $\mathrm{CeO}_{2}$ in Pt nanoparticle/mesoporous $\mathrm{CeO}_{2}$ Catalyst. In Situ X-ray Spectroscopy and Diffraction Studies under Redox (H-2 and O-2) Atmospheres. J Phys Chem C 117:26608-26616. doi:10.1021/jp407280e

91. Michalak WD, Krier JM, Alayoglu S et al (2014) CO oxidation on PtSn nanoparticle catalysts occurs at the interface of Pt and Sn oxide domains formed under reaction conditions. J Catal 312:17-25. doi:10.1016/j.jcat.2014.01.005

92. Davis BH (2001) Fischer-Tropsch synthesis: current mechanism and futuristic needs. Fuel Process Technol 71:157-166. doi:10. 1016/S0378-3820(01)00144-8

93. Riedel T, Claeys M, Schulz H et al (1999) Comparative study of Fischer-Tropsch synthesis with $\mathrm{H}-2 / \mathrm{CO}$ and $\mathrm{H}-2 / \mathrm{CO}_{2}$ syngas using Fe- and Co-based catalysts. Appl Catal 186:201-213. doi:10.1016/S0926-860X(99)00173-8

94. Melaet G, Ralston WT, Li C-S et al (2014) Evidence of highly active cobalt oxide catalyst for the Fischer-Tropsch synthesis and $\mathrm{CO}_{2}$ hydrogenation. J Am Chem Soc 136:2260-2263. doi: $10.1021 / \mathrm{ja} 412447 \mathrm{q}$

95. Alayoglu S, Beaumont SK, Zheng F et al (2011) $\mathrm{CO}_{2}$ hydrogenation studies on $\mathrm{Co}$ and $\mathrm{CoPt}$ bimetallic nanoparticles under reaction conditions using TEM, XPS and NEXAFS. Top Catal 54:778-785. doi:10.1007/s11244-011-9695-9

96. Hilmen AM, Schanke D, Holmen A (1996) TPR study of the mechanism of rhenium promotion of alumina-supported cobalt Fischer-Tropsch catalysts. Catal Lett 38:143-147. doi:10.1007/ BF00806560

97. Ronning M, Tsakoumis NE, Voronov A et al (2010) Combined $\mathrm{XRD}$ and XANES studies of a Re-promoted Co/gamma- $\mathrm{Al}_{2} \mathrm{O}_{3}$ catalyst at Fischer-Tropsch synthesis conditions. Catal Today 155:289-295. doi:10.1016/j.cattod.2009.10.010

98. Borg O, Hammer N, Eri S et al (2009) Fischer-Tropsch synthesis over un-promoted and re-promoted gamma- $\mathrm{Al}_{2} \mathrm{O}_{3}$ supported cobalt catalysts with different pore sizes. Catal Today 142:70-77. doi:10.1016/j.cattod.2009.01.012

99. Xin HL, Alayoglu S, Tao R et al (2014) Revealing the atomic restructuring of Pt-Co nanoparticles. Nano Lett 14:3203-3207. doi:10.1021/nl500553a

100. Beaumont SK, Alayoglu S, Specht C et al (2014) Combining in Situ NEXAFS Spectroscopy and $\mathrm{CO}_{2}$ Methanation Kinetics to study Pt and Co nanoparticle catalysts reveals key insights into the role of platinum in promoted cobalt catalysis. J Am Chem Soc 136:9898-9901. doi:10.1021/ja505286j

101. Conner W, Falconer J (1995) Spillover in heterogeneous catalysis. Chem Rev 95:759-788. doi:10.1021/cr00035a014

102. Baker LR, Kennedy G, Van Spronsen M et al (2012) Furfuraldehyde hydrogenation on titanium oxide-supported platinum nanoparticles studied by sum frequency generation vibrational spectroscopy: acid-base catalysis explains the molecular origin of strong metal-support interactions. J Am Chem Soc 134:14208-14216. doi:10.1021/ja306079h

103. Kennedy G, Baker LR, Somorjai GA (2014) Selective amplification of $\mathrm{C}=\mathrm{O}$ bond hydrogenation on $\mathrm{Pt} / \mathrm{TiO}_{2}$ : catalytic reaction and sum- frequency generation vibrational spectroscopy studies of crotonaldehyde hydrogenation. Angew Chem Int Ed 53:3405-3408. doi:10.1002/anie.201400081

104. Na K, Musselwhite N, Cai X et al (2014) Promotional effects of mesoporous zeolites with pt nanoparticle catalysts during reforming of methylcyclopentane. J Phys Chem A. doi:10.1021/ jp501775q
105. Ko MK, Frei H (2004) Millisecond FT-IR spectroscopy of surface intermediates of $\mathrm{C}_{2} \mathrm{H}_{4}$ hydrogenation over $\mathrm{Pt} / \mathrm{Al}_{2} \mathrm{O}_{3}$ catalyst under reaction conditions. $\mathrm{J}$ Phys Chem $\mathrm{B}$ 108:1805-1808. doi:10.1021/jp030920e

106. Sivasankar N, Frei H (2011) Direct observation of kinetically competent surface intermediates upon ethylene hydroformylation over $\mathrm{Rh} / \mathrm{Al}_{2} \mathrm{O}_{3}$ under reaction conditions by time-resolved fourier transform infrared spectroscopy. J Phys Chem C 115:7545-7553. doi:10.1021/jp112391n

107. Dent AJ (2002) Development of time-resolved XAFS instrumentation for quick EXAFS and energy-dispersive EXAFS measurements on catalyst systems. Top Catal 18:27-35. doi:10. 1023/A: 1013826015970

108. Shishido T, Asakura H, Amano F et al (2009) In situ timeresolved energy-dispersive XAFS study on reduction behavior of Pt supported on $\mathrm{TiO}_{2}$ and $\mathrm{Al}_{2} \mathrm{O}_{3}$. Catal Lett 131:413-418. doi:10.1007/s10562-009-0095-8

109. Gross E, Shu X-Z, Alayoglu S et al (2014) In situ IR and X-ray high spatial-resolution microspectroscopy measurements of multistep organic transformation in flow microreactor catalyzed by Au nanoclusters. J Am Chem Soc 136:3624-3629. doi:10. 1021/ja412740p

110. Ji XZ, Zuppero A, Gidwani JM, Somorjai GA (2005) The catalytic nanodiode: gas phase catalytic reaction generated electron flow using nanoscale platinum titanium oxide Schottky diodes. Nano Lett 5:753-756. doi:10.1021/n1050241a

111. Park JY, Somorjai GA (2006) The catalytic nanodiode: detecting continous electron flow at oxide-metal interfaces generated by a gas-phase exothermic reaction. ChemPhysChem 7:1409-1413. doi:10.1002/cphc. 200600056

112. Niehus H, Heiland W, Taglauer E (1993) Low-energy ionscattering at surfaces. Surf Sci Rep 17:213-303. doi:10.1016/ 0167-5729(93)90024-J

113. Harmsen JMA, Jansen WPA, Hoebink J et al (2001) Coke deposition on automotive three-way catalysts studied with LEIS. Catal Lett 74:133-137. doi:10.1023/A:1016633114136

114. Jansen WPA, van der Gon AWD, Wijers GM et al (2002) A differentially pumped pressure cell for in situ low-energy ion scattering analysis of catalysts during reactions. Rev Sci Instrum 73:354-361. doi:10.1063/1.1433949

115. Panitz J (1978) Imaging atom-probe mass-spectroscopy. Prog Surf Sci 8:219-262. doi:10.1016/0079-6816(78)90002-3

116. Bagot PAJ, de Bocarme TV, Cerezo A, Smith GDW (2006) 3D atom probe study of gas adsorption and reaction on alloy catalyst surfaces I: instrumentation. Surf Sci 600:3028-3035. doi:10. 1016/j.susc.2006.05.026

117. Bagot PAJ, Cerezo A, Smith GDW (2007) 3D atom probe study of gas adsorption and reaction on alloy catalyst surfaces II: results on Pt and Pt-Rh. Surf Sci 601:2245-2255. doi:10.1016/j. susc. 2007.03.030

118. Gaussmann A, Kruse N (1991) Co-Induced Structural-Changes of Pd Particle Surfaces. Catal Lett 10:305-315. doi:10.1007/ BF00772085

119. De Bocarme TV, Moors M, Kruse N et al (2009) Surface segregation of $\mathrm{Au}-\mathrm{Pd}$ alloys in $\mathrm{UHV}$ and reactive environments: Quantification by a catalytic atom probe. Ultramicroscopy 109:619-624. doi:10.1016/j.ultramic.2008.11.007

120. De Smit E, Swart I, Creemer JF et al (2008) Nanoscale chemical imaging of a working catalyst by scanning transmission X-ray microscopy. Nature 456:222-239. doi:10.1038/nature07516 